\title{
SEISMIC UPGRADING OF EXISTING RC BUILDINGS BY SLENDER STEEL SHEAR PANELS: A FULL-SCALE EXPERIMENTAL INVESTIGATION
}

\author{
A. Formisano ${ }^{1}$, G. De Matteis ${ }^{2, *}$ S. Panico ${ }^{3}$ and F. M. Mazzolani ${ }^{4}$ \\ ${ }^{I}$ PhD, Department of Structural Engineering, University of Naples “Federico II", Naples, Italy \\ ${ }^{2}$ Associate Professor, Department of Design, Rehabilitation and Control of Architectural Structures, \\ University of Chieti/Pescara "G. d'Annunzio", Pescara, Italy \\ ${ }^{3}$ PhD, Department of Structural Engineering, University of Naples "Federico II”, Naples, Italy \\ ${ }^{4}$ Full Professor, Department of Structural Engineering, University of Naples "Federico II”, Naples, Italy \\ * (Corresponding author: E-mail:demattei@unina.it)
}

Received: 27 November 2006; Revised: 2 May 2007; Accepted: 22 June 2007

\begin{abstract}
In the present paper the seismic upgrading of an existing RC structure by using slender steel shear panels is examined. Based on a preliminarily experimental evaluation of the performance of the bare RC structure, an ad hoc design procedure has been developed in the framework of the performance based design methodology. The applied device, whose configuration has been defined also according to both simplified and refined numerical analyses, is able to significantly enhance both the strength and the stiffness of the primary structure. It has been installed within a reaction steel frame, positioned into the bare RC structure, which is composed by members designed in order to remain in elastic regimen under the tension field action developed by plates. Since the original $\mathrm{RC}$ module was not able to withstand significant values of horizontal forces, the reinforcing of both the first level beam and the foundation beam by means of coupled channel steel profiles and threaded bars has been done. Finally, in order to assess the reliability of the proposed intervention, a full scale cyclic experimental test has been performed on the upgraded structure, confirming the effectiveness of the adopted technique as well as the validity of the proposed design procedure.
\end{abstract}

Keywords: Slender steel shear panels, seismic upgrading, GLD building, experimental test, tension field mechanism, plate buckling

\section{INTRODUCTION}

In the framework of new seismic design approaches for upgrading existing reinforced concrete buildings, the development of innovative intervention techniques, based on either the reinforcement of existing structural elements or the introduction of new resisting systems, the metal-based technology approach can be considered very profitable [1]. Such a technique is founded on the energy dissipation capacity of special metallic devices able to achieve or improve the structural safety of the original structure under seismic actions.

Within this category, the solution based on using metal shear panels can result particularly effective, due to the limited weight, the reduced volume obstruction, the easy insertion and the meaningful structural contribution offered by the applied devices in terms of strength, stiffness and ductility. In addition, it is important to observe that the self-weight of steel panels is rather low, if compared with the one of a reinforced concrete shear wall, determining in this way a reduction of gravitational loads and therefore of seismic actions transmitted to the foundation.

Nowadays, metal shear panels adopted in seismic applications can be subdivided in two main behavioural classes: 1) the so-called "compact" panels, mainly made of low strength metallic materials (LYS steel or pure aluminium) and properly stiffened in order to avoid elastic shear buckling phenomena, which have been recently proposed for high steel buildings and also for reinforcement of RC buildings [2]; 2) the "slender" shear panels, made of thin steel plates, which have been widely studied and applied both in North America and in Japan mainly for applications 
into new buildings [3]. In particular, the latter typology can be effectively used in case of primary structures characterized by limited lateral stiffness and reduced over-strength. In fact, slender shear panels may behave as stiffening devices also, rather than as hysteretic dampers only. As a consequence, the contribution provided by shear panels could significantly reduce the damageability of the primary structure, which is usually a key point in case of old existing structures.

\section{STEEL PLATE SHEAR WALLS}

\section{$2.1 \quad$ General}

Shear walls realized with either slender or compact shear panels are able to offer significant resistance against seismic actions, conferring high ductility, stable hysteretic characteristics and good initial stiffness to the structure in which they are installed. Besides, they could provide a significant over-strength and also ability to absorb seismic energy input in a wide deformation range. In shear panels the energy dissipation takes place mainly for shear mechanism, by means of either pure shear stress action (Figure 1a) or tension field action (Figure 1b) [4]. In the latter, owing to the high slenderness of the plate, premature shear buckling in the elastic field occurs and the lateral shear forces are carried by means of diagonal tensile stresses developing in the web plates parallel to the directions of the principal stresses. Such a behaviour, which is typical of slender shear panels, produces both a poor dissipative behaviour, with a pronounced slip-type hysteretic response, and a strong flexural interaction with beams and columns of the primary frame. On the other hand, a pure shear dissipative mechanism is of concern for compact shear panels, it allowing both a stable inelastic cyclic behaviour and a uniform yielding spread over the entire plate. In order to have a pure shear dissipative mechanism, shear panels should be designed and ribbed in such a way to avoid any buckling phenomenon up to the required plastic deformation level.
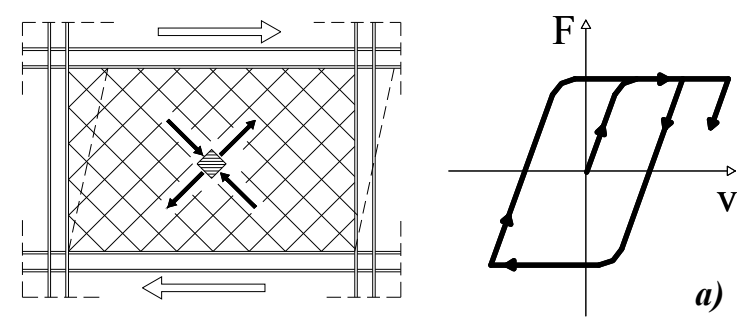

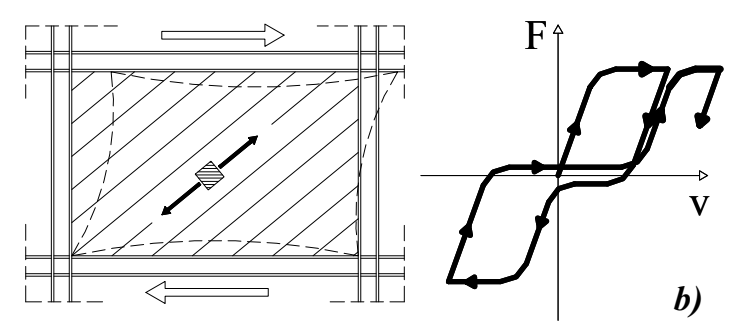

b)

Figure 1. Shear Energy Dissipation Mechanisms: Pure Shear (a) and Tension Field (b)

In addition, shear panels with pure shear mechanism are also able to enhance the energy dissipation capacity of the whole structure, acting as sacrificial devices, absorbing a large amount of seismic input energy and protecting the primary framed structure from relevant structural damages. Therefore, they can act as hysteretic dampers, whose dissipative function is activated by the inter-storey drifts occurring during the deformation of the structure subjected to horizontal actions.

Although characterised by a poor dissipative behaviour, in the present study, the use of shear walls made of slender steel plates for improving the characteristics of strength and stiffness of existing structures is investigated. 


\subsection{Application of Slender Shear Panels}

When acting as bracing system, slender steel plate shear walls can be conformed according to two different configurations [5]. The first solution, defined as standard system, is the one in which the connections among members are schematised as pinned joints (Figure 2a): in such a case, which refers typically to steel structures, the only seismic-resistant system is represented by the shear wall, while the remaining part of the structure must be checked in order to carry vertical loads only. Considering that also hinged beam-to-column connections are usually able to absorb some amount of the flexural moment, from $20 \%$ to $70 \%$ of the plastic moment of the connected beam, the primary structure participates to the absorption of the acting horizontal actions. In this case the members must be opportunely rigid and resistant so that the dissipation mechanism can develop correctly through the whole surface of shear panels: therefore it is necessary that the beams are designed for remaining in the elastic field while the columns do not suffer buckling phenomena.

The second solution, defined as dual system, foresees that the beam-to-column connections are of moment-resisting type (Figure $2 b$ ): the reaction frame participates significantly to the absorption of horizontal actions, providing an additional contribution to the lateral resistance given by steel shear walls.

In such a case, which refers to framed (either steel or reinforced concrete) structures, the members have to be checked to support the tension field mechanism produced by the panel, with particular attention to the formation of plastic hinges in the surrounding members. Considering that also the base framed structure participates to the absorption of lateral forces, it should be checked that it is actually able to absorb a part of these actions, which must be determined according to the ratio between the lateral stiffness of the two systems (primary structure and shear wall).

STEEL PLATE SHEAR WALL

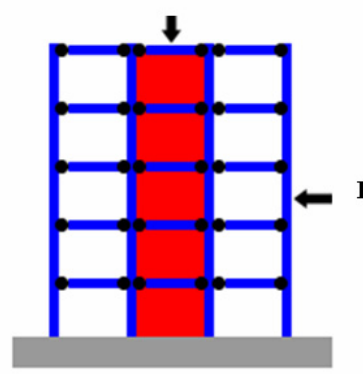

STEEL PLATE SHEAR WALL

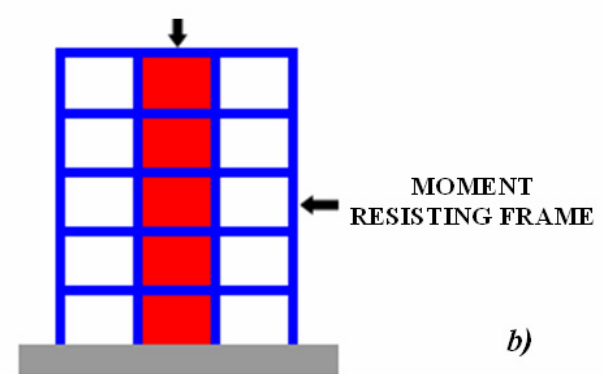

Figure 2. Shear Walls Configurations: a) Standard System; b) Dual System

In such a framework, when framed RC buildings are of concern, metal shear panels should be inserted into a reaction steel frame in order to allow their installation in the primary structure.

The connection between shear panels and the members of the surrounding frame, which can be of simple or moment-resistant type, can be realized by using bolts or by welding the panel to appropriate plates fixed to the beams and columns.

Comparing the current system with the traditional steel stiffening and strengthening techniques (concentric or eccentric bracings), it has to be observed that the former allows to realize easily openings by the insertion of opportune stiffening elements surrounding the opening surface (Figure 3a). Another solution that can be effectively employed for allowing the presence of large openings in steel walls is to use two separate steel shear walls connected among them through the floors beams (Figure 3b). 

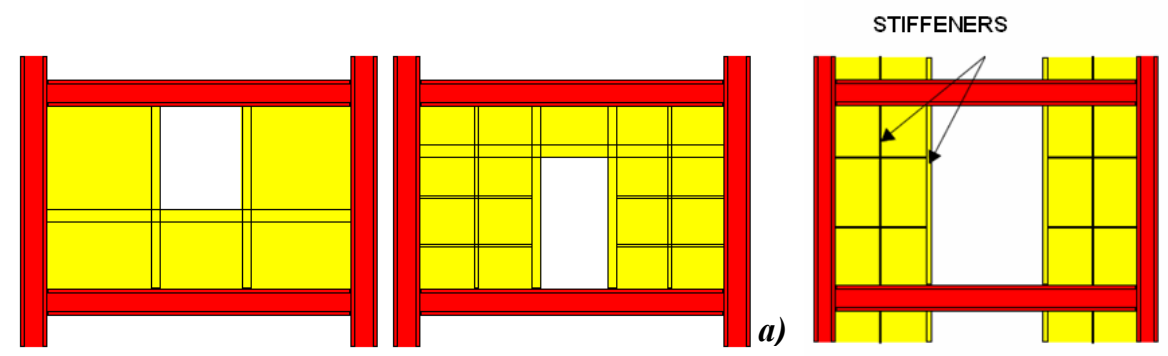

COUPLED BEAMS RIGIDLY CONNECTED TO COLUMNS

Figure 3. Openings in Simple Steel Plate Shear Walls (a) and Adoption of Coupled Steel Plate Shear Walls (b)

\section{THE BUILDING UNDER INVESTIGATION}

In the field of the seismic retrofitting of existing buildings, the ILVA-IDEM research project (acronym of Intelligent DEMolition) represents an innovative approach aiming at evaluating the effectiveness of different anti-seismic devices based on the use of metallic materials. In particular, the activity foresees the execution of different experimental tests on a reinforced concrete building located in the ex-industrial area ILVA of Bagnoli (Figure 4), located in the suburb of Naples, which is currently interested by a re-qualification process [6]. The building under examination, which has been designed in order to withstand only vertical loads, has rectangular dimensions and is developed on two levels, with not practicable coverage floor.

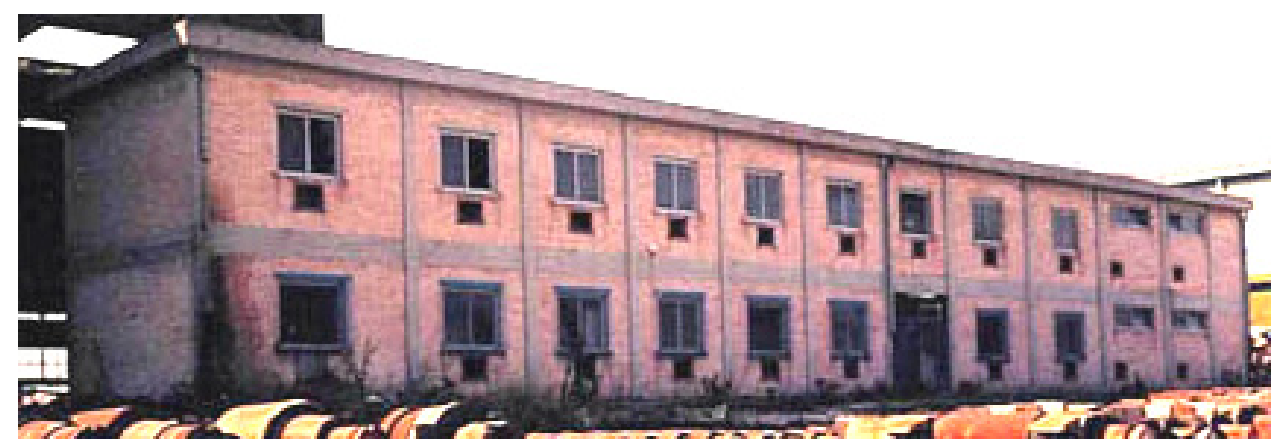

Figure 4. The Original Building

In order to analyse different retrofitting techniques, the building has been divided into six substructures (modules) by means of cuts performed at the floor levels, removing preliminarily cladding and partition walls (Figure 5).

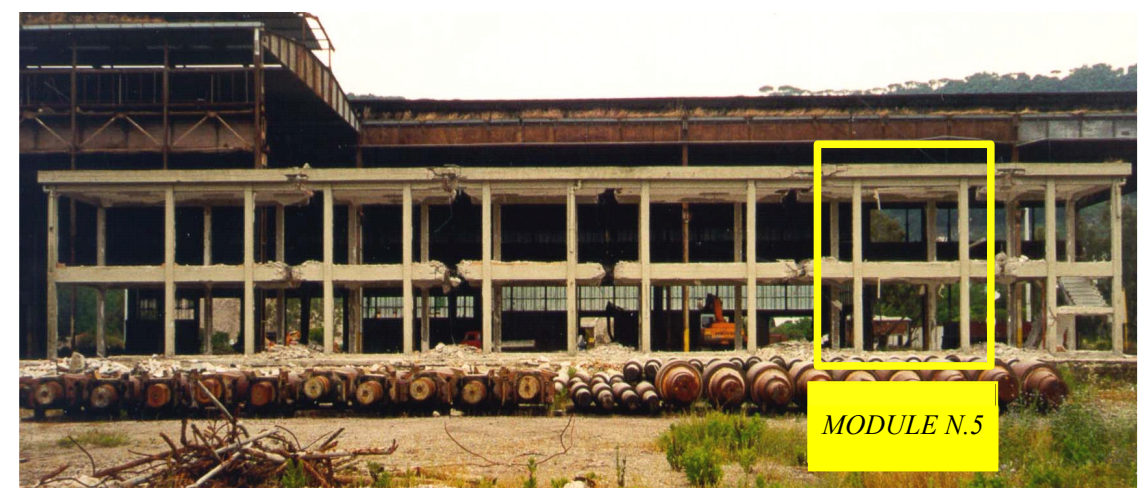

Figure 5. The Division in Sub-structures (Modules) 
In this context, only the employment of shear panels is analysed. In particular, steel shear panels, which are connected with bolted connections to an external reaction steel frame, are longitudinally placed within the RC module identified with number 5 in Figure 5. A general view of both the two levels carpentry and the two orthogonal structural sections of the sub-structure is depicted in Figures 6 and 7, respectively.

The emergent beams, which are placed along the perimeter in longitudinal direction and support a mixed-concrete slab (Figures $8 \mathrm{a}$ and $\mathrm{b}$ ), includes $2 \phi 8$ on the upper side and $2 \phi 10+1 \phi 12$ on the lower one. The strength in transversal direction is supplied by $30 \times 30 \mathrm{~cm}$ columns (Figure 8c), having $4 \phi 12$ longitudinal bars and stirrups $\phi 8 / 30 "$, connected by the floor slab only.
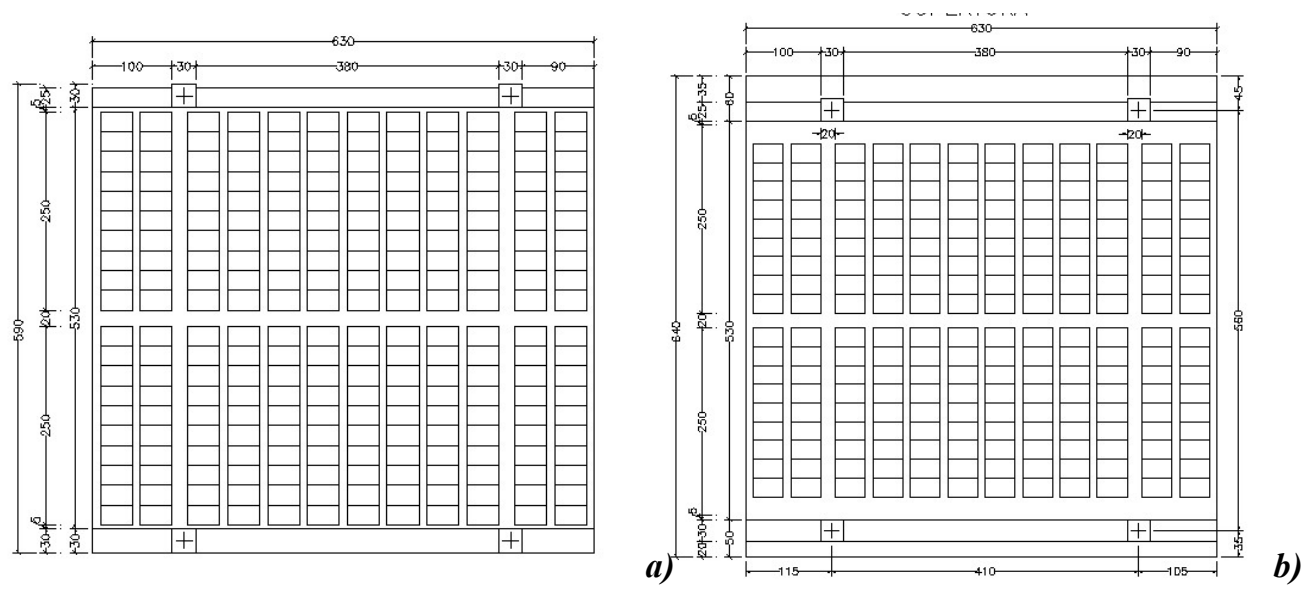

Figure 6. Carpentries of the First (a) and Second Floor (b)
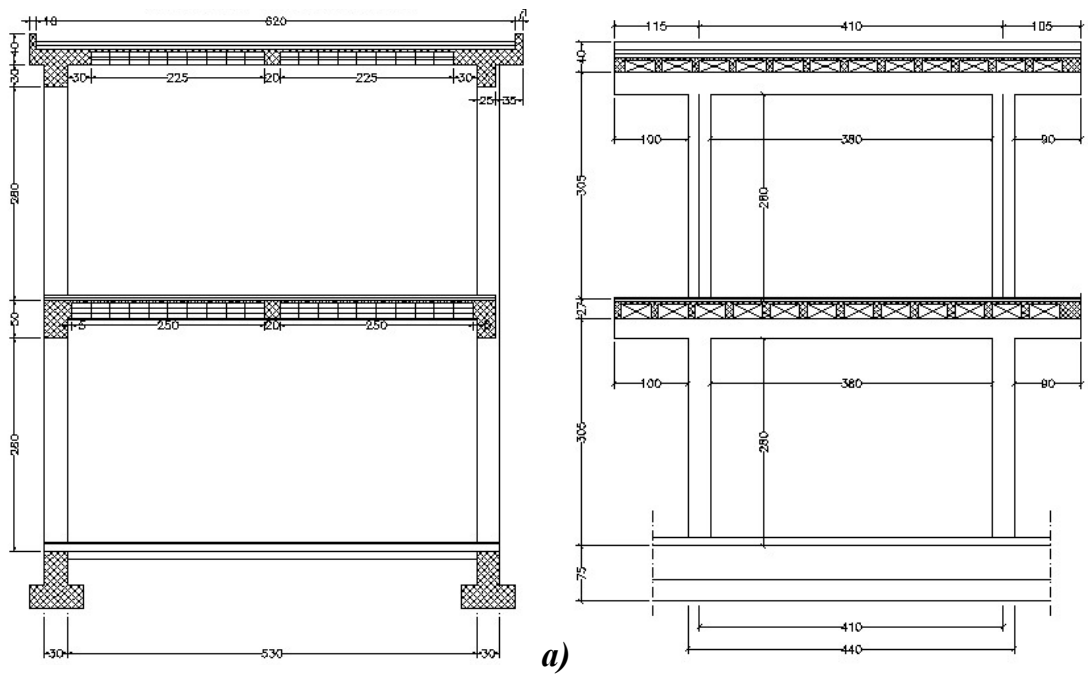

b)

Figure 7. Transversal (a) and Longitudinal (b) Section of the Module Under Study 

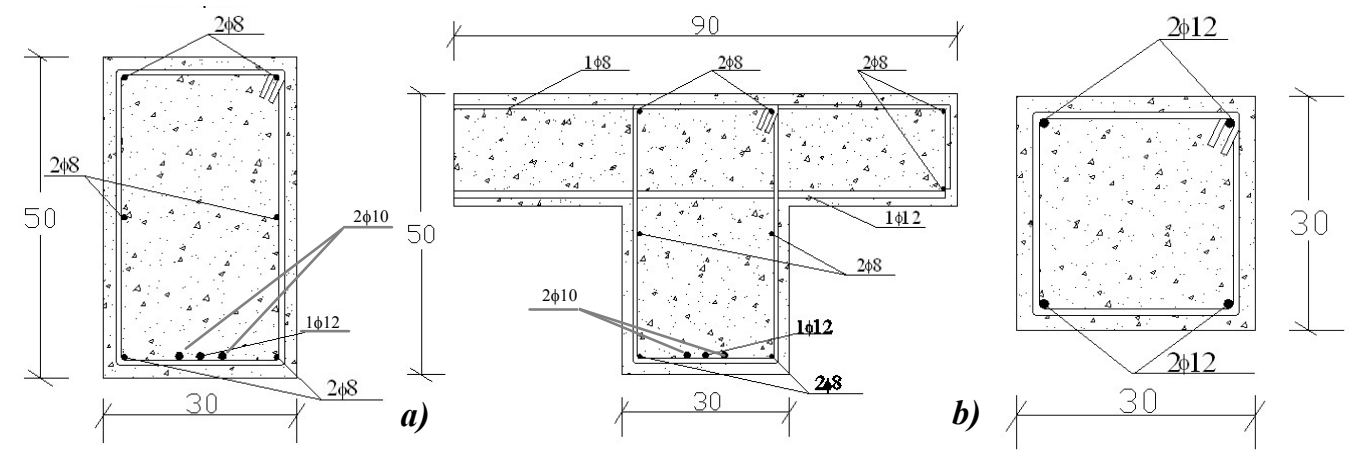

c)

Figure 8. Representative Sections of the Fifth Module:

First (a) and Second (b) Level RC Beam and Column (c)

Aiming at defining the mechanical characteristics of the base materials composing the RC structure, laboratory tests have been carried out at the Department of Structural Engineering of the University of Naples "Federico II" on specimens directly extracted from the structure. Three compression tests (Figure 9) have provided for the concrete an average ultimate strength and Young modulus equal to 20.9 MPa and $17155 \mathrm{MPa}$, respectively (Table 1). The mechanical properties of the steel bars have been obtained by performing tensile tests, whose results are reported in Table 2.
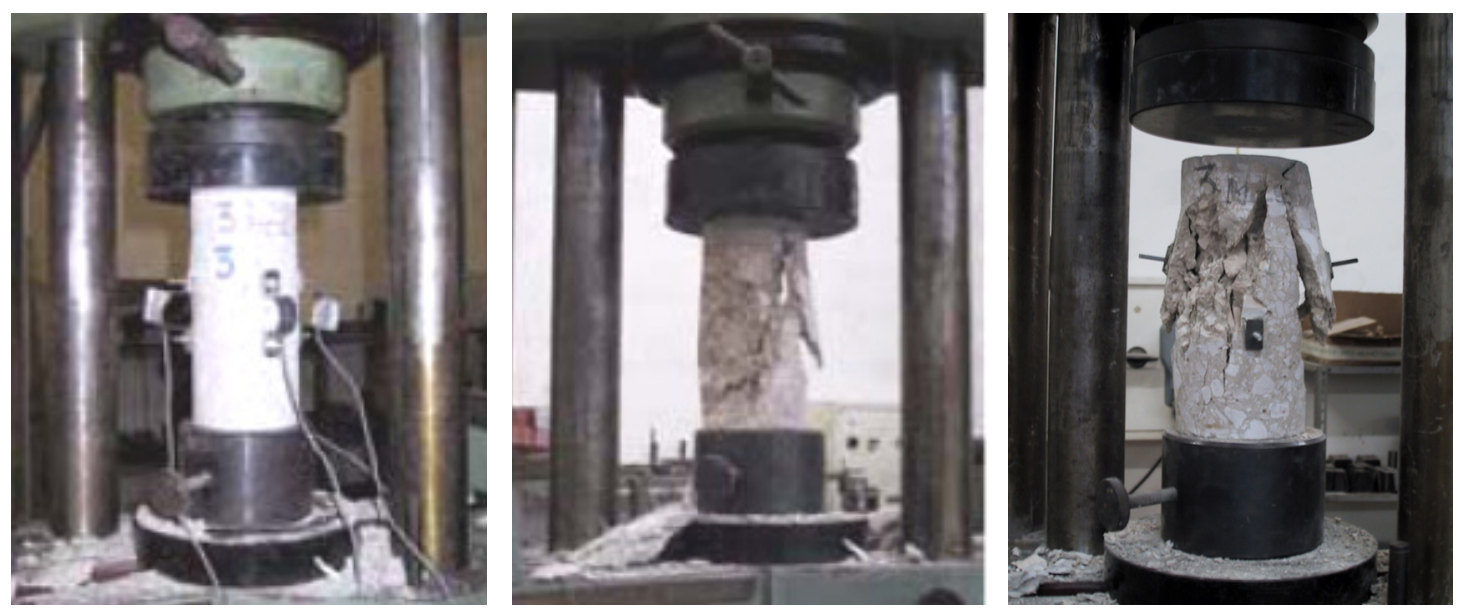

Figure 9. Compression Test on Concrete Cylindrical Specimen

Table 1. Results of Compression Tests on Concrete Specimens

\begin{tabular}{|c|c|c|c|}
\hline \multirow{2}{*}{ Specimen } & $\begin{array}{c}\text { Unit } \\
\text { weight }\end{array}$ & $\begin{array}{c}\text { Elastic } \\
\text { modulus }\end{array}$ & Strength \\
\cline { 2 - 4 } & {$\left[\mathrm{Kg} / \mathrm{m}^{3}\right]$} & {$[\mathrm{MPa}]$} & {$[\mathrm{MPa}]$} \\
\hline 1 & 2244 & 18035 & 20.9 \\
\hline 2 & - & 16990 & 21.4 \\
\hline 3 & 2235 & 16442 & 20.3 \\
\hline Average & 2239 & 17155 & 20.9 \\
\hline
\end{tabular}


Table 2. Results of Tensile Tests on Steel Bars

\begin{tabular}{|c|c|c|c|c|c|c|}
\hline Specimen & Diameter & $\mathrm{L}$ & $\mathrm{N}_{\mathrm{v}}$ & $\mathrm{N}_{\text {ult }}$ & $\sigma_{\text {ult }}$ & $\sigma_{\mathrm{v}}$ \\
\hline $\mathrm{N}$. & {$[\mathrm{mm}]$} & {$[\mathrm{mm}]$} & {$[\mathrm{kN}]$} & {$[\mathrm{kN}]$} & {$[\mathrm{MPa}]$} & {$[\mathrm{MPa}]$} \\
\hline 1 & 8 & 1040 & 29.0 & 33.0 & 656.5 & 576.9 \\
\hline 2 & 8 & 975 & - & 41.0 & 815.7 & - \\
\hline 3 & 8 & 500 & 23.1 & 33.4 & 664.5 & 459.6 \\
\hline 4 & 10 & 558 & 39.5 & 59.2 & 753.8 & 502.9 \\
\hline 5 & 10 & 520 & 38.9 & 58.8 & 748.7 & 495.3 \\
\hline 6 & 10 & 485 & - & 62.7 & 798.3 & - \\
\hline 7 & 12 & 850 & 44.1 & 73.8 & 652.5 & 389.9 \\
\hline 8 & 12 & 570 & 53.1 & 82.2 & 726.8 & 469.5 \\
\hline 9 & 12 & 860 & 53.0 & 79.0 & 698.5 & 468.6 \\
\hline
\end{tabular}

The selected structural module has been preliminarily tested, without reaching the complete collapse of the system, by means of a pushover test, employing two hydraulic jacks having a capacity of 30 tons (Figure 10).

The test results, reported in terms of Force-Displacement curve of the first storey in Figure 11, provide useful information on the ultimate strength and the exact lateral stiffness levels offered by the primary structure.
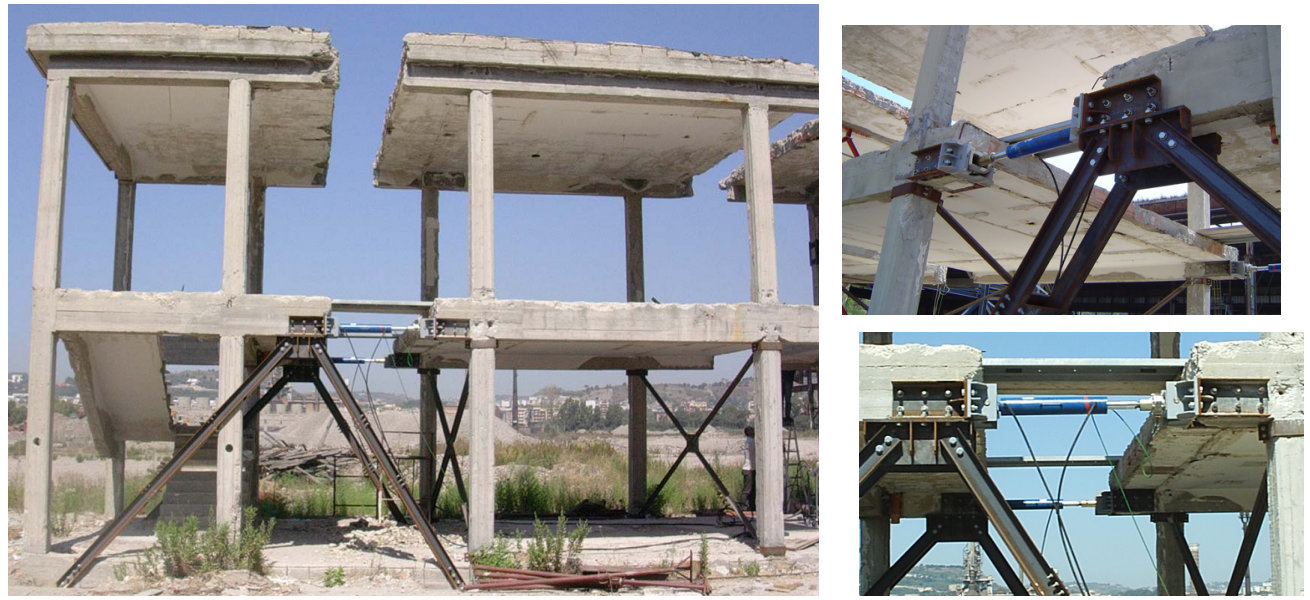

Figure 10. Pushover Test on the Module under Study

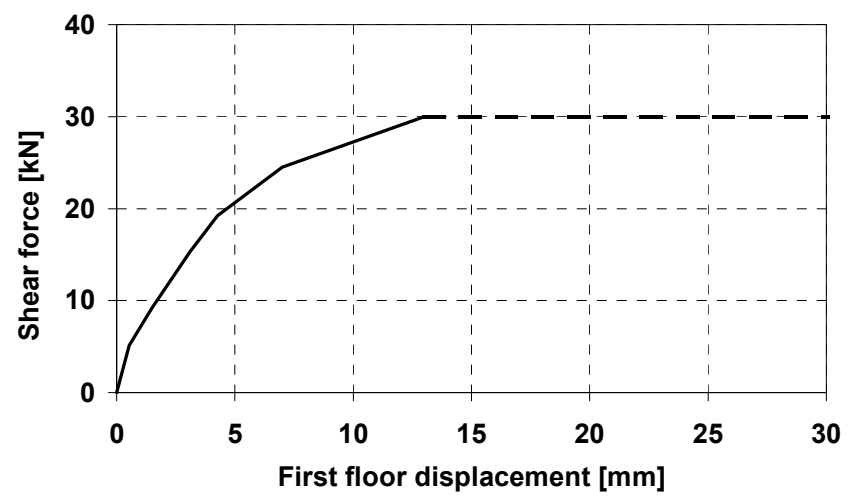

Figure 11. Result of the Experimental Pushover Test 


\section{THE RETROFITTING DESIGN}

The choice of an appropriate seismic consolidation strategy depends on the determination of specific performance objectives to be assured as well as on the determination of the reasons why the original structure is not able to provide the required performance. Once the structural deficiencies have been determined, a preliminary retrofitting design can be developed [7]. In particular, after the determination of the displacement level required to the original structure under the design earthquake and the spectral displacement target for the reinforced structure, the shear panel characteristics able to absolve this task can be defined [8,9]. In order to define the actual geometry of shear panels to be adopted, a sophisticated finite element model has been implemented by means of the ABAQUS v. 6.4 non linear numerical code [10], it being described in detail in [11]. The material used for panel is DX56D steel, whose stress-strain curve is reported in Figure 12, which is employed as a base material for producing cold-formed thin walled sheeting and profiles.

On the basis of existing analytic simplified formulations [12, 13], the panel dimensions have been determined as $b=600 \mathrm{~mm}, d=2400 \mathrm{~mm}$ and $s=1.15 \mathrm{~mm}$. In order to guarantee a $b / d$ ratio lower than 0.8 , that is indicated as the lower bound of the aspect ratio beyond which the development of a correct plastic mechanism is not developed, the insertion of appropriate transversal rectangular stiffeners (height of $100 \mathrm{~mm}$ and thickness of $4 \mathrm{~mm}$ ) along the whole panel length has been foreseen. Therefore, the panel has been subdivided into six parts having $b=600 \mathrm{~mm}$ and $d=400$ $\mathrm{mm}$. The sub - panels are connected to each other and to the surrounding frame by means of M14 bolts, having a pitch of $50 \mathrm{~mm}$ and a edges distance of $25 \mathrm{~mm}$ (Figure 13). In order to assess the effectiveness of the adopted connecting systems, preliminary tensile tests on two $150 \times 250 \mathrm{~mm}$ panel portions, connected by means of $100 \times 150 \mathrm{~mm}$ fishplates and six M14 bolts, have been carried out (Figure 14a). The corresponding results in terms of force (F) - relative displacement $(\Delta)$ are given in Figure 15.

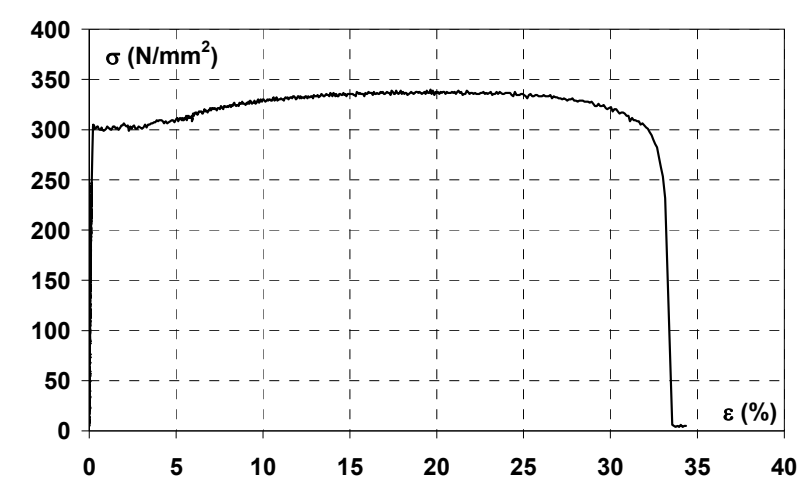

Figure 12. $\sigma-\varepsilon$ Curve of the Adopted Steel 


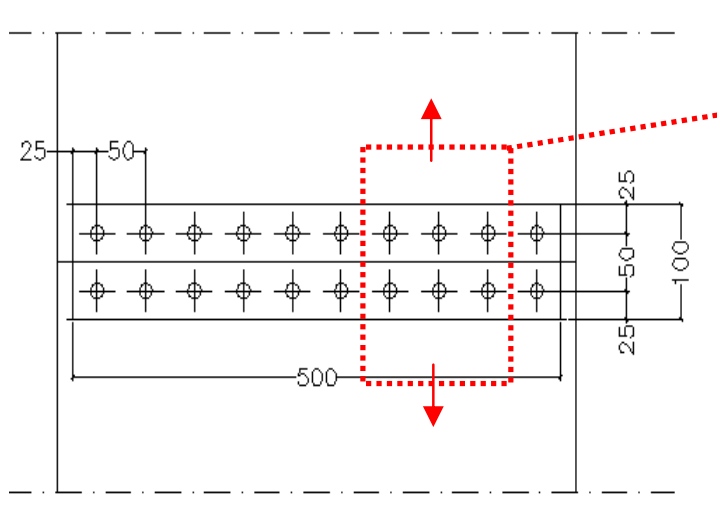

Figure 13. Details of the Panel Connection
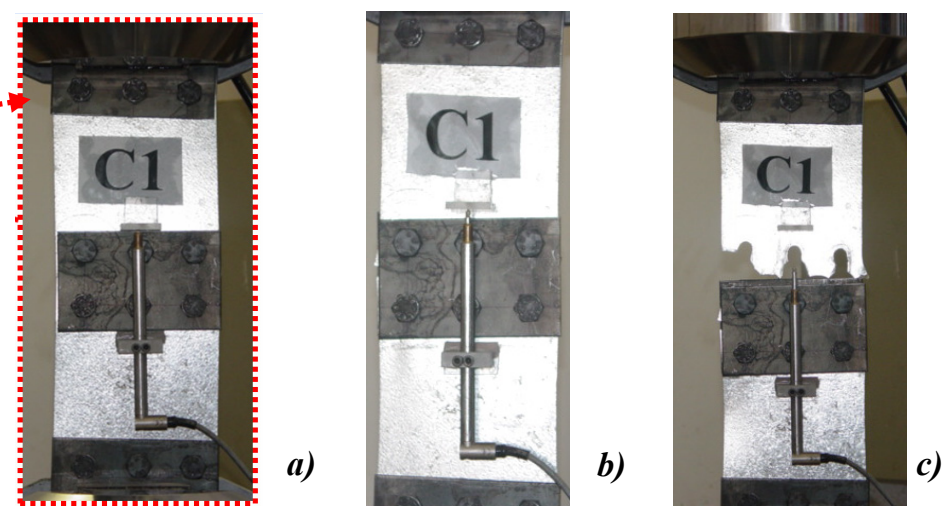

Figure 14. Connection Specimen Before (a), During (b) and After (b) the Test

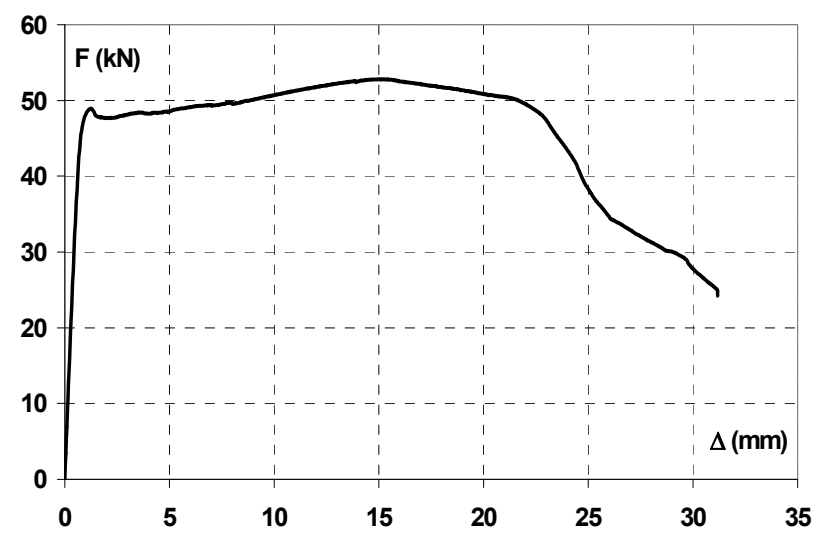

Figure 15. The Experimental Response of the Connection

It is apparent that the shear strength of connections is higher than the yielding resistance of the plate because of the occurrence of the block tearing mechanism, which determines a significant increment of the effective sheeting net section (Figure 14c). Also a significant ductility of the adopted connection, which make it able to restore the panel continuity, is noticeable. In order to confirm the validity of the proposed design solution and for evaluating possible interaction problems between the RC structure and the steel parts, a global analyses of the retrofitted structure, where the shear plates have been modelled according to the "strip model" theory [13], has been performed [14]. 


\section{THE EXPERIMENTAL TEST}

\subsection{System Set-up}

The proposed technique has been validated by a full scale experimental test. In order to install the steel shear panel into the RC frame, a surrounding hinged steel frame, constituted by members realised with UPN180 coupled profiles, has been introduced (Figure 16).

In order to have an appropriate panel response, represented by the development of a tension field mechanism with an inclination of $45^{\circ}$, the shear plate has been subdivided into two parts, having an aspect ratio equal to 0.50 , due to the insertion of intermediate UPN 240 coupled beams, whose configuration is depicted in Figure 17.
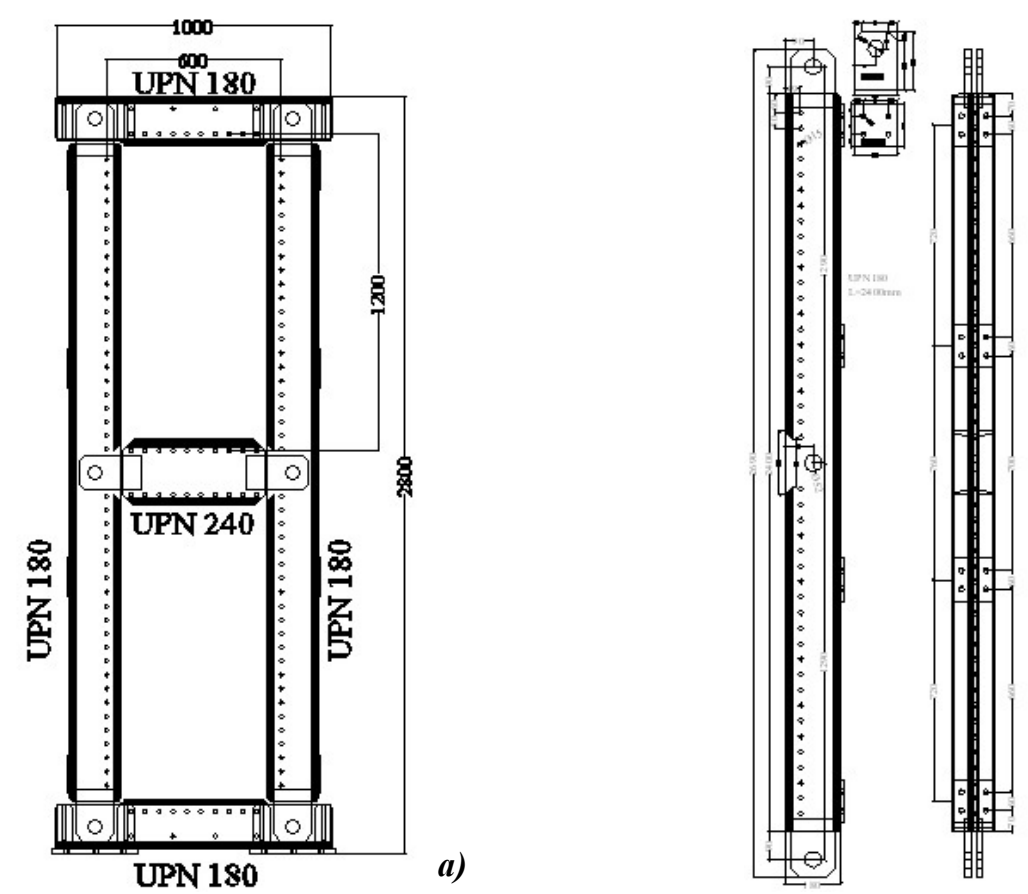

b)

Figure 16. Lateral Reaction Steel Frame

(a) and Particular of Adopted Columns (b)
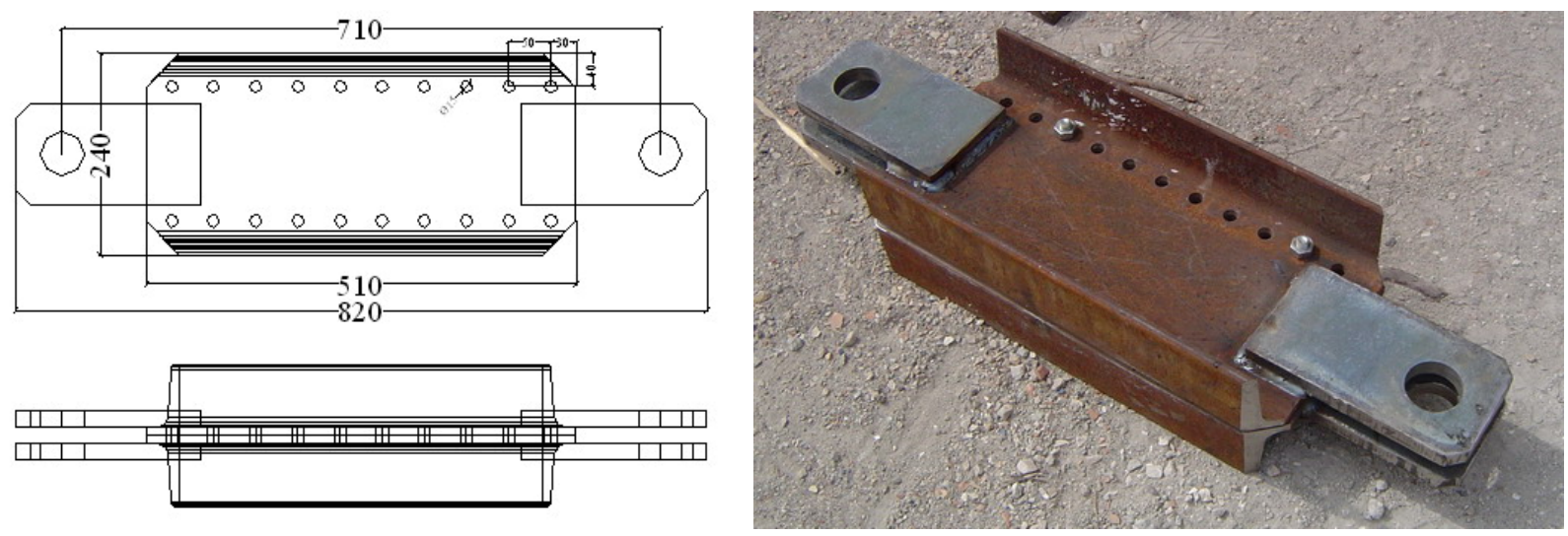

Figure 17. The Intermediate Beam

In particular, aiming at ensuring that the columns could sustain the normal boundary stresses associated with the tension field, considering hinged connections between frame members, the following equation must be satisfied: 
$M_{p f}=\frac{\sigma_{t y} \cdot t \cdot\left(\frac{d}{2}\right)^{2} \cdot \cos ^{2} \Theta}{8}$

where $t$ and $d$ are the panel thickness and height, respectively, while $\Theta$ is the inclination angle of tensile bands. The Eq. (1), which would allow using a column depth equal to $1 / 2$ of the actual one, has been determined considering the columns as supported on three points. In such a way the bending moment applied to the vertical elements is equal to $1 / 4$ of the one characterising the scheme without the intermediate member [12], thus determining smaller dimensions of the columns. On the other hand, the beams have to be characterised by an adequate flexural stiffness and strength to allow an uniform tension field in the shear panel surface. The minimum plastic resistance of the beam may be determined by the following relationship:

$M_{p f}=\frac{\sigma_{t y} \cdot t \cdot b^{2} \cdot \cos ^{2} \Theta}{8}$

where $b$ is the panel width.

The steel frame columns have been connected to RC foundation beams by means of four UPN 220 profiles, adequately stiffened by reinforcing steel plates, and six threaded passing M16 bolts (Figure 18).
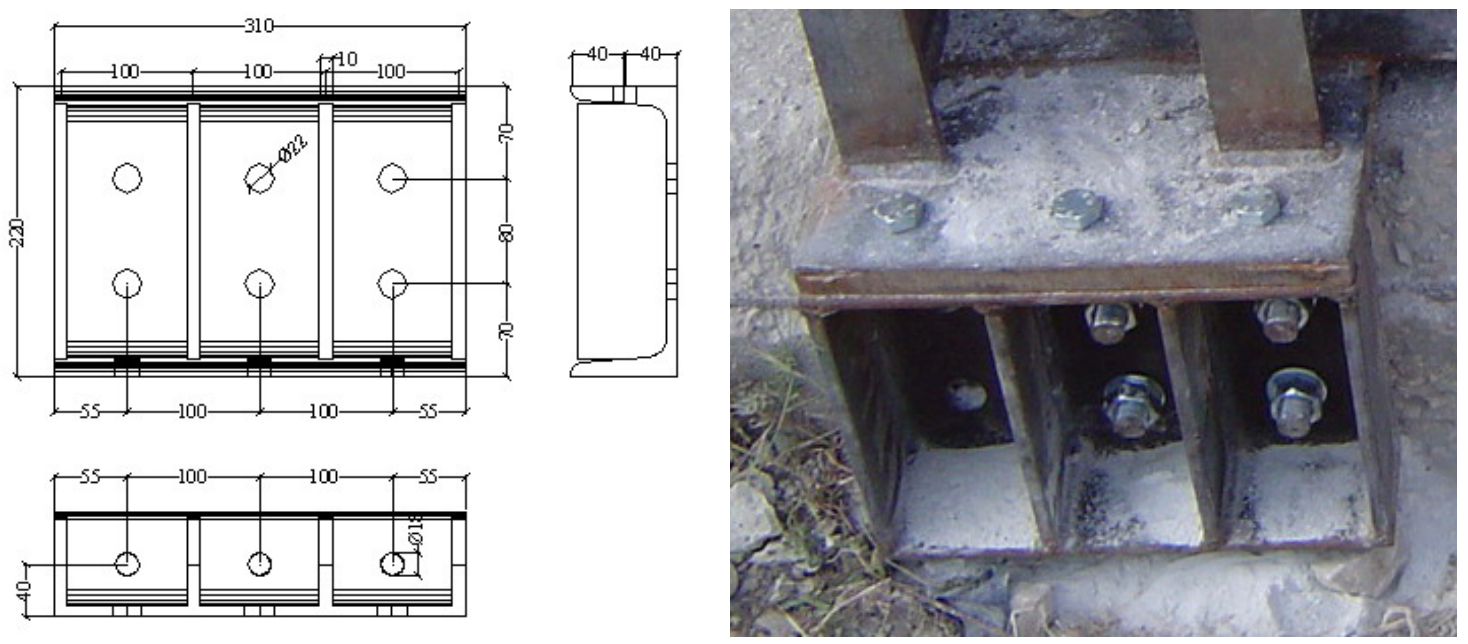

Figure 18. Reaction Steel Frame - Foundation Beam Connection

Moreover, in order to allow the transfer of the forces carried out by the steel panel (approximately 10 times greater than the one of the bare structure) the jacketing of the $\mathrm{RC}$ beam, by using two UPN220 profiles, has been executed (Figure 19).

In particular, the connection between the upper member of the reaction steel frame and the $\mathrm{RC}$ beam reinforcing one is realised with the system reported in Figure 20, while the details of the hinged beam-to-column connection are illustrated in Figure 21.

The final configuration of the applied system is represented in Figure 22, where the connection details and the intermediate stiffeners of the panel are also visible. In the same figure the installation of St. Andrew cross bracings in the transversal direction of the module is visible, they being able to avoid structural torsional effects during the loading test. 

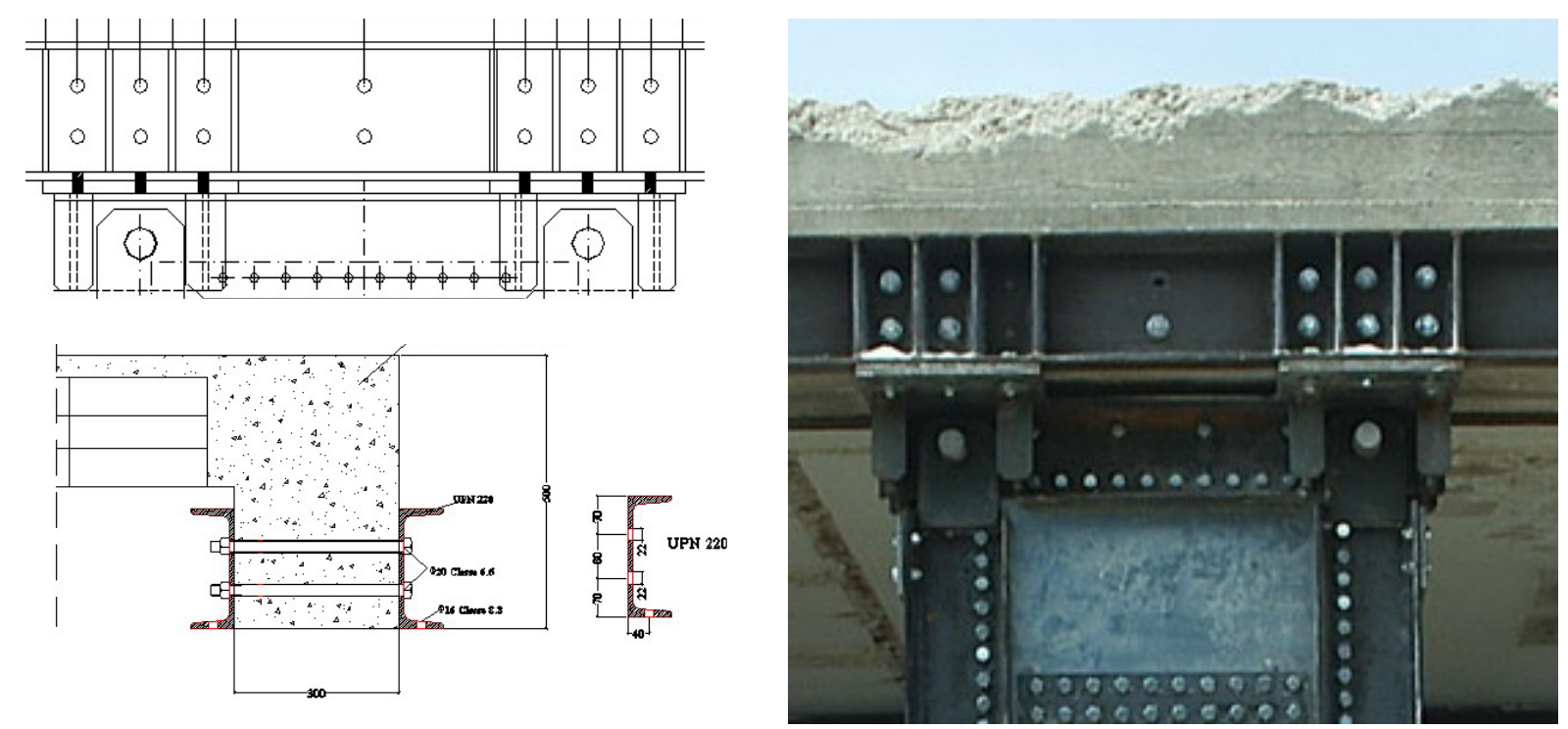

Figure 19. Reaction Steel Frame - RC Beam Connection
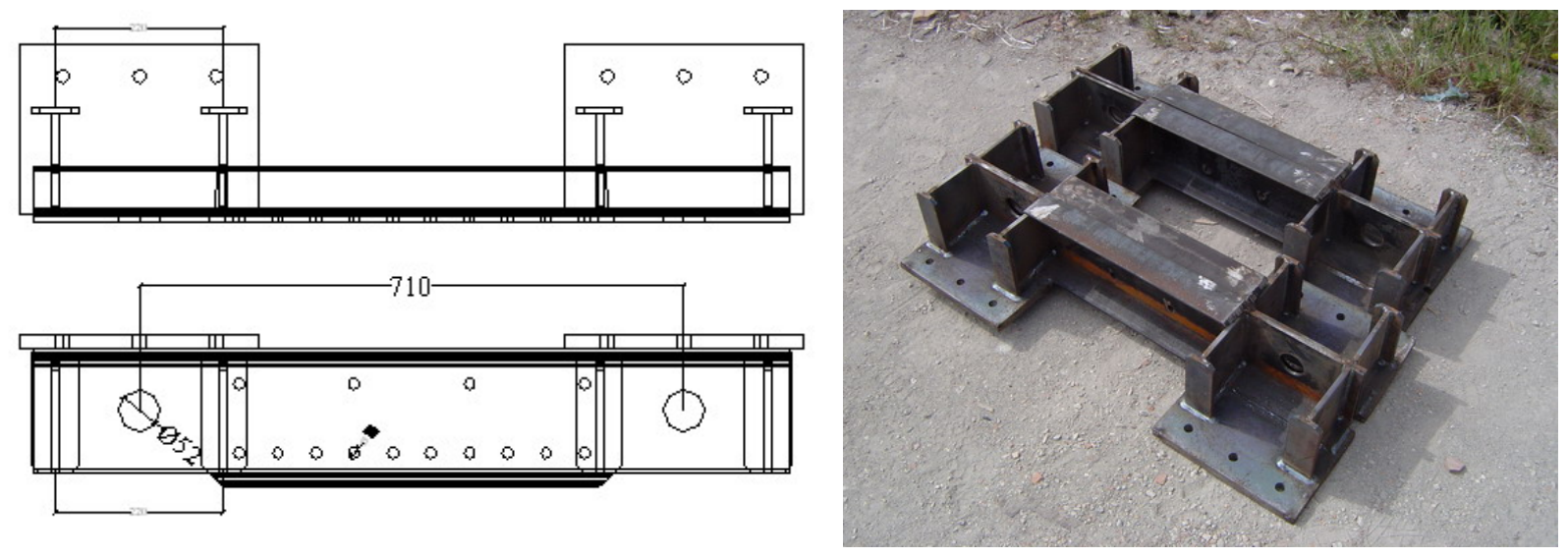

Figure 20. The Connection System between the Jacketing Steel Beam and the Upper one of the Reaction Frame 


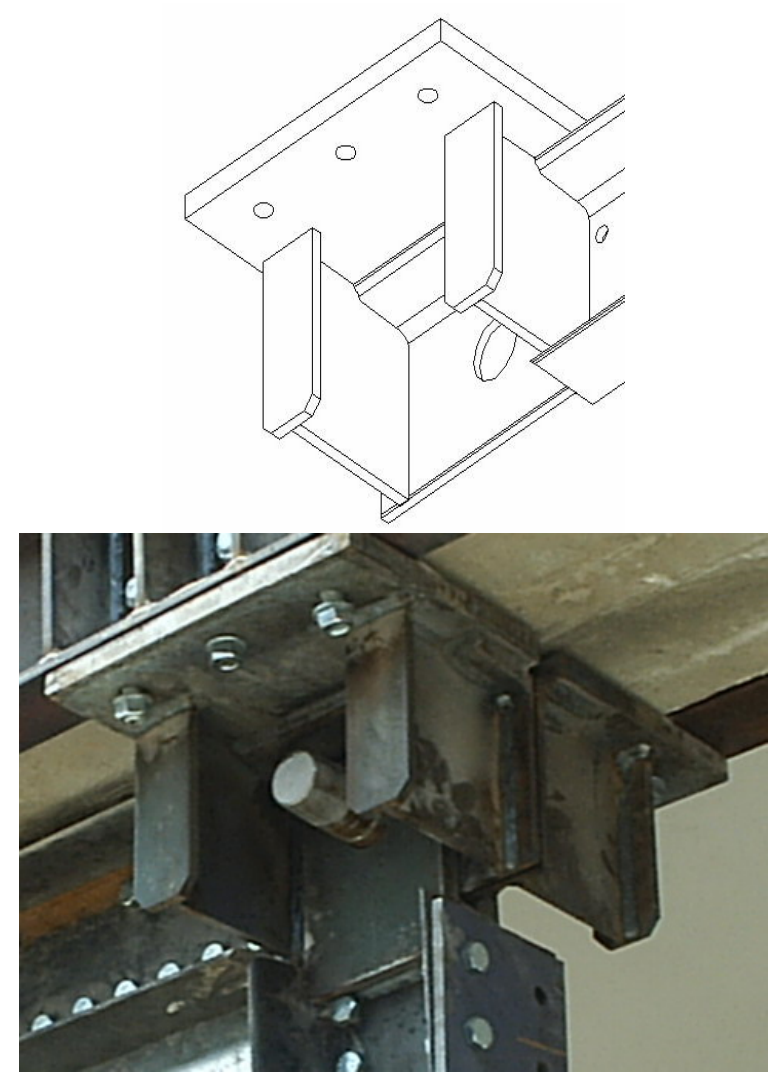

Figure 21. Details of the Hinged Beam-to-column Connection

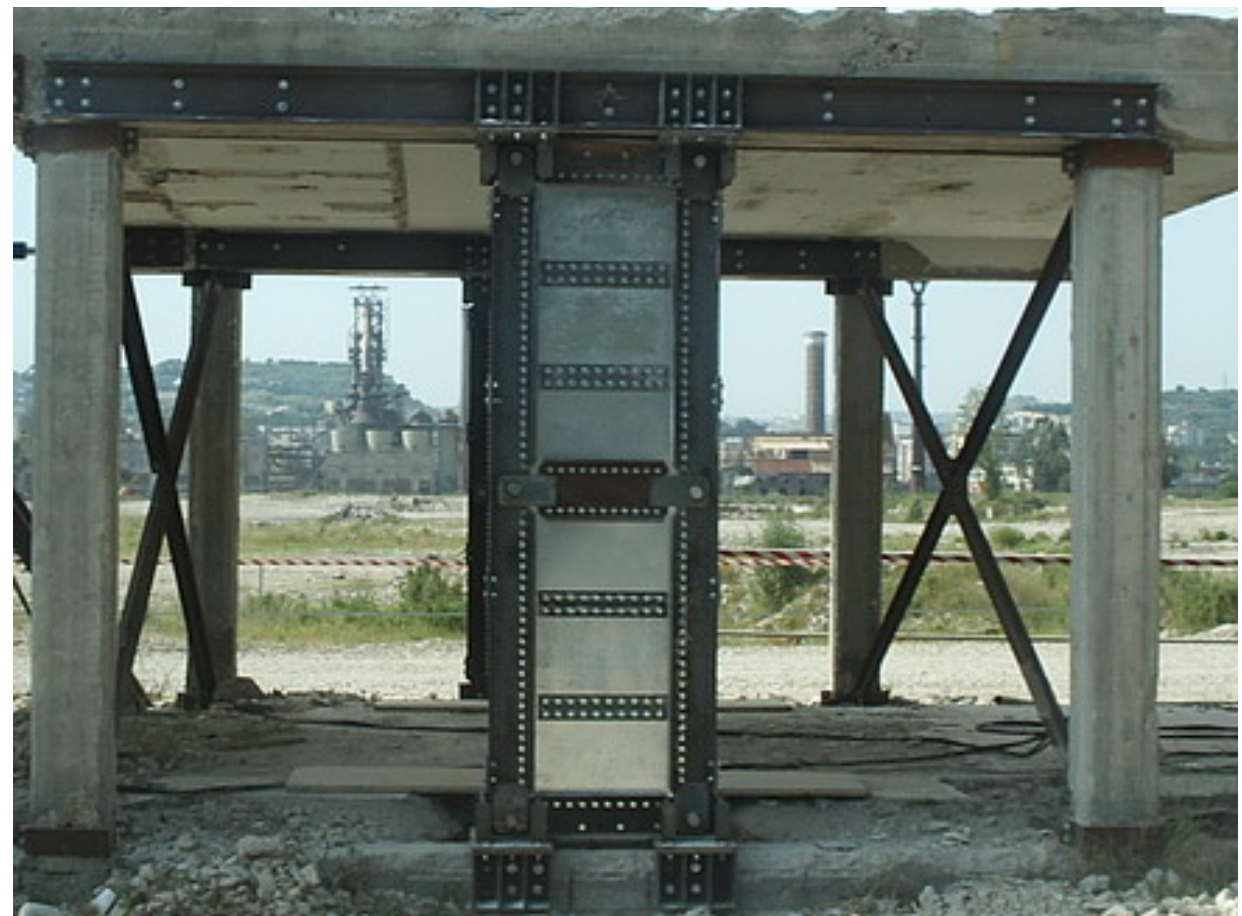

Figure 22. Global View of the Retrofitted Structure

The retaining structure, which has been applied to the sixth module of the original RC building, is obtained by connecting steel profiles to the foundation beam and to the first level RC beam end (Figure 23). 


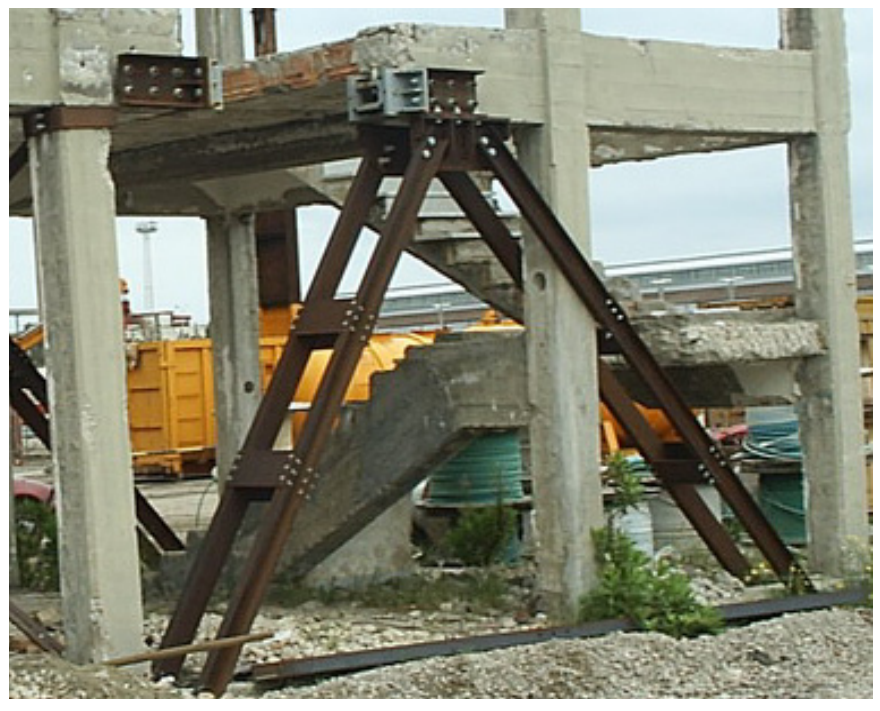

Figure 23. The Retaining Steel Structure

The lateral load has been applied to the reinforced structure by using hydraulic jacks, which were able to apply tensile and compression actions equal to 200 and $300 \mathrm{kN}$, respectively.

In the experimental test several measurement devices (continuous transducers) have been employed in order to acquire the following absolute displacements (Figure 24):

- first level floor on both sides of the structure (P3);

- reinforcing steel beam (P4);

- shear wall stiffeners (P5- P7-P8) and intermediate

- UPN 240 beam (P6);

- foundation of shear panel (P9).

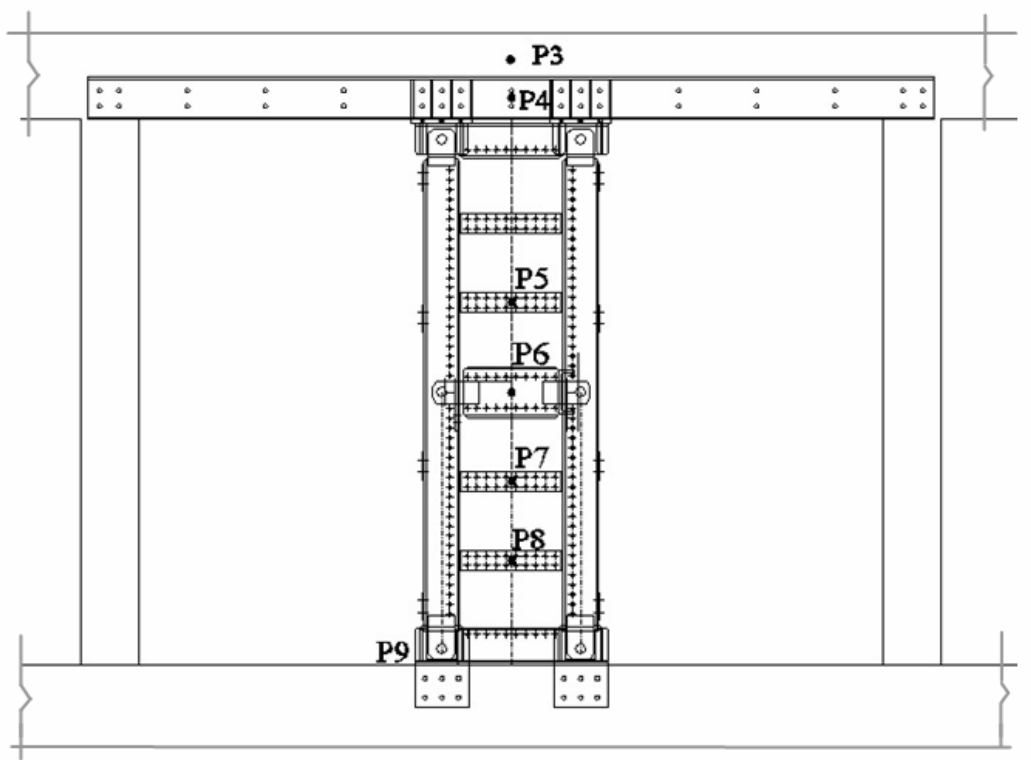

Figure 24. Location of Measurement Instruments 
A global view of the used measurement instruments is reported in Figure 25.

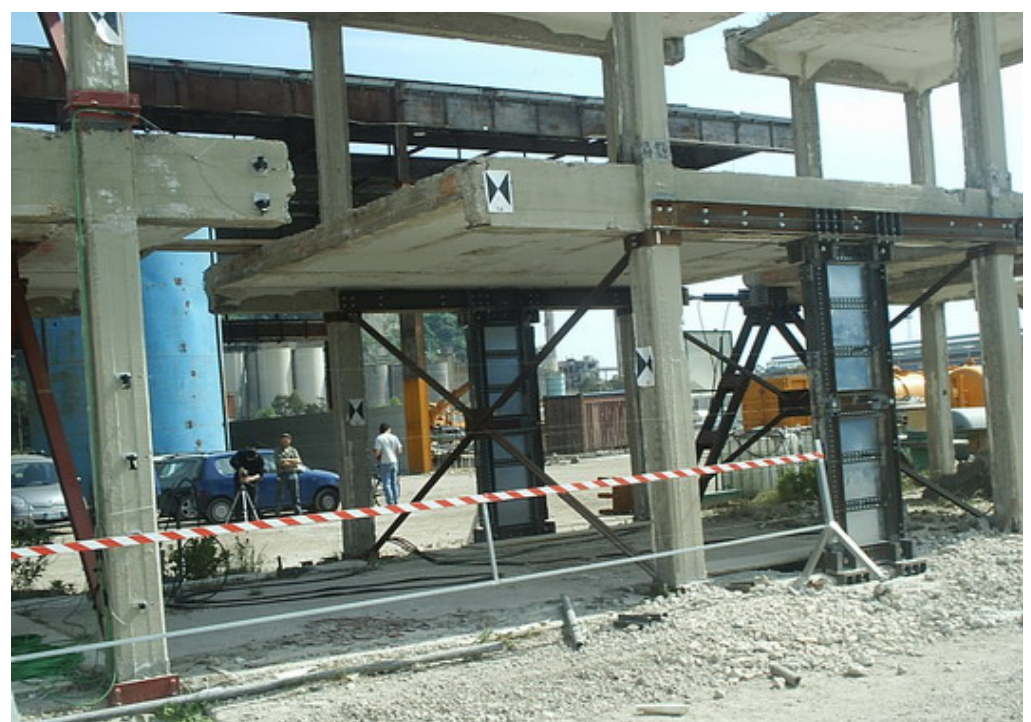

Figure 25. Global View of the Measurement Devices Applied on the Upgraded Structure

\subsection{The Experimental Behaviour}

In the experimental test a cyclic loading history under quasi-static conditions has been applied (Figure 26). The load has been increased of $20 \mathrm{kN}$ for each cycle up to the last one, where the increment has been of $60 \mathrm{kN}$. All loading cycles have been symmetric up to the attainment of 200 $\mathrm{kN}$; hence only the compression load has been increased up to $300 \mathrm{kN}$.

During the test, any important difference between the displacements measured by two transducers located at the two opposite sides of the building occurred. In addition, the displacements of the transducers fixed on the RC beam and on the reinforcing steel profile have provided the same values, confirming the effectiveness of the connection created between the primary structure and the reinforcing steel beams. The displacements relieved at the base of the steel plate shear wall were very small, providing a maximum amplitude of $1 \mathrm{~mm}$ when the peak load of $300 \mathrm{kN}$ was attained.

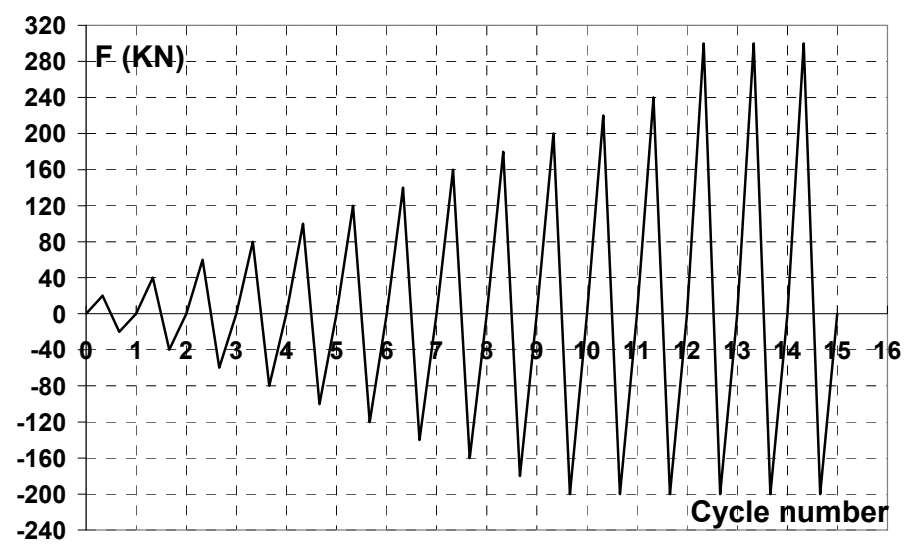

Figure 26. The Applied Loading History

The result of the experimental test in terms of applied force versus the first storey displacement (P3 transducer) is depicted in Figure 27. The behaviour of the retrofitted structure is significantly improved, showing an increase of the initial stiffness and ultimate strength equal to $400 \%$ and $1000 \%$, respectively. Also, the deformation capacity of the structure results to be very large, 
without the involvement of any brittle collapse mode up to a deformation amplitude equal to 85 $\mathrm{mm}$, corresponding an inter-storey drift equal to 3.5\%. Finally, it should be observed that the dissipation capacity of the structure is quite satisfactory, showing a combined mechanism between plastic hinges in the beam-to-column joint of the RC frame and plastic deformation of tensioned diagonals of the applied steel shear panel.

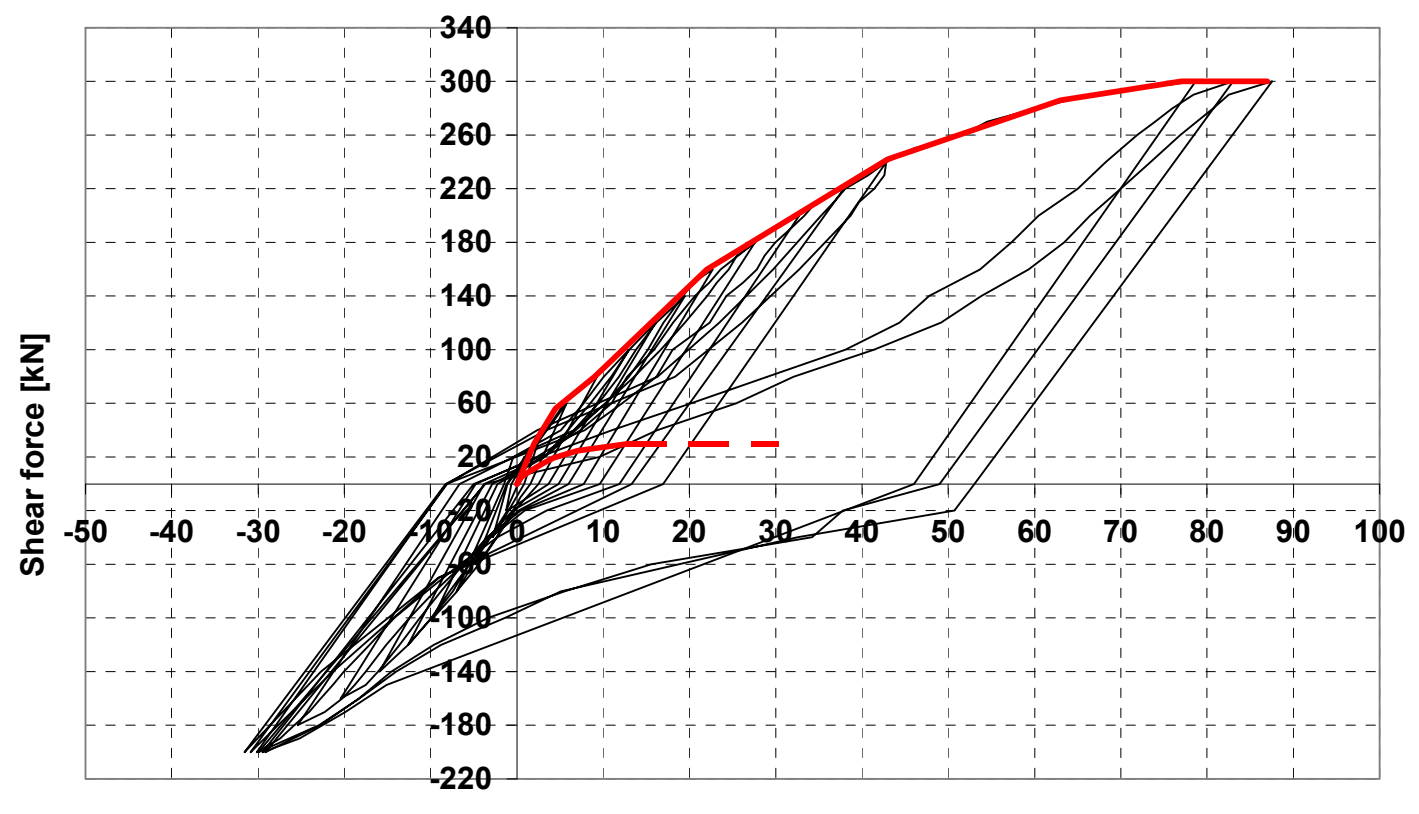

First floor displacement [mm]

Figure 27. The Experimental Response of the Retrofitted Structure

In the Figures 28-to-33, a detailed representation of significant phenomena occurred in the shear panels during the test is presented. In particular, in the second cycle, for a displacement of $2.94 \mathrm{~mm}$, the occurrence of buckling in the upper sub-panel was evident (see Figure 28). Such a phenomenon was due to the global flexural action on the shear wall which, due to the compression load generating in the steel column and the development of slips in the beam-to-column connection of the retaining steel frame, caused the buckling of the panel portions subjected to the maximum compression loading.
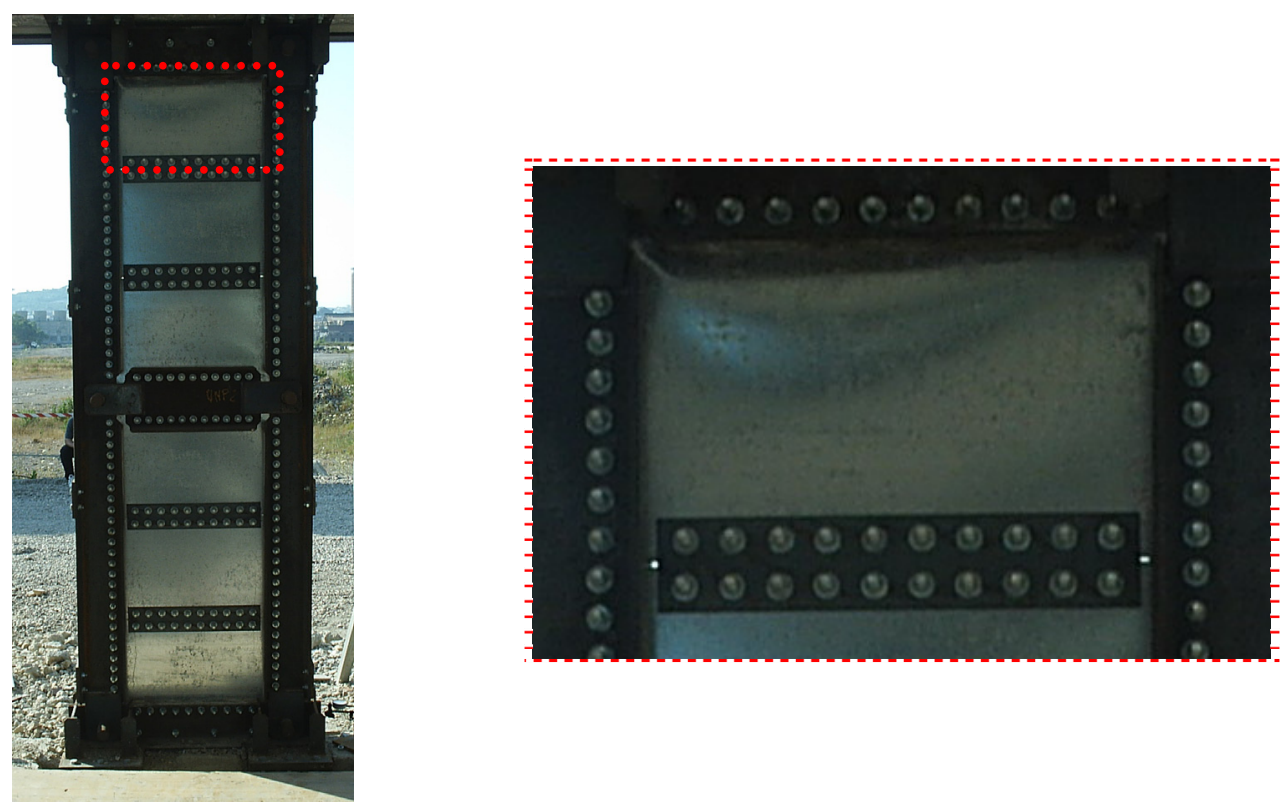

Figure 28. The Shear Panel Response during the Second Cycle of the Loading Test 
In the third cycle, for an applied total force of $60 \mathrm{kN}$ and a displacement of about $6 \mathrm{~mm}$, the instability of each panel portions, with a more remarkable development of the buckled shape in the upper one, occurred (Figure 29).

In the fifth cycle, when a global lateral action equal to $100 \mathrm{kN}$, producing a structural displacement of $13 \mathrm{~mm}$, has been applied, the buckling behaviour involved more panel portions (Figure 30), while starting from the ninth cycle permanent waves developed on the surface of each sub-panel. In particular, at this stage, which is characterized by a total force of $220 \mathrm{kN}$ and a displacement of $37.90 \mathrm{~mm}$, the tension field mechanism was activated also in the upper panel portion (Figure 31).
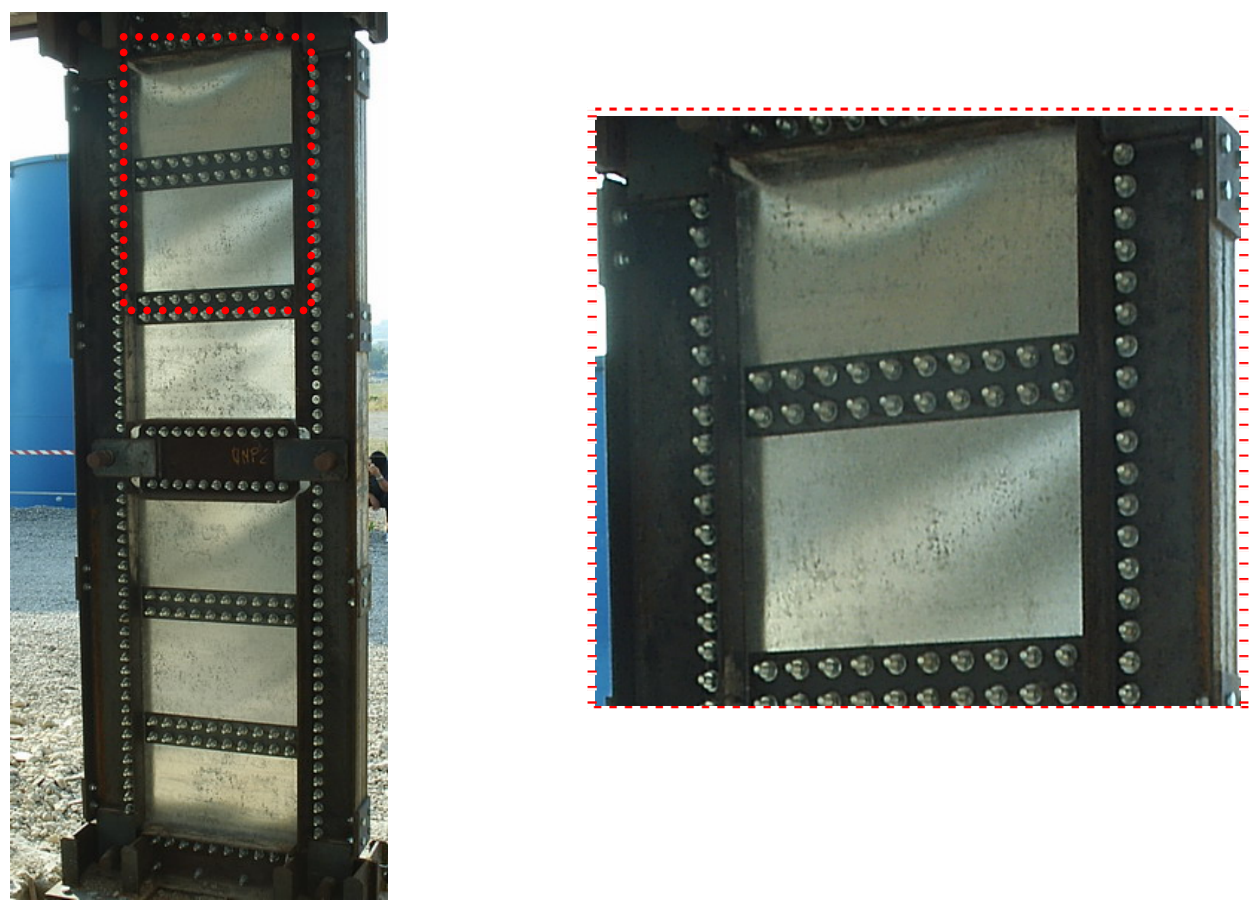

Figure 29. The Shear Panel Response during the Third Cycle of the Loading Test
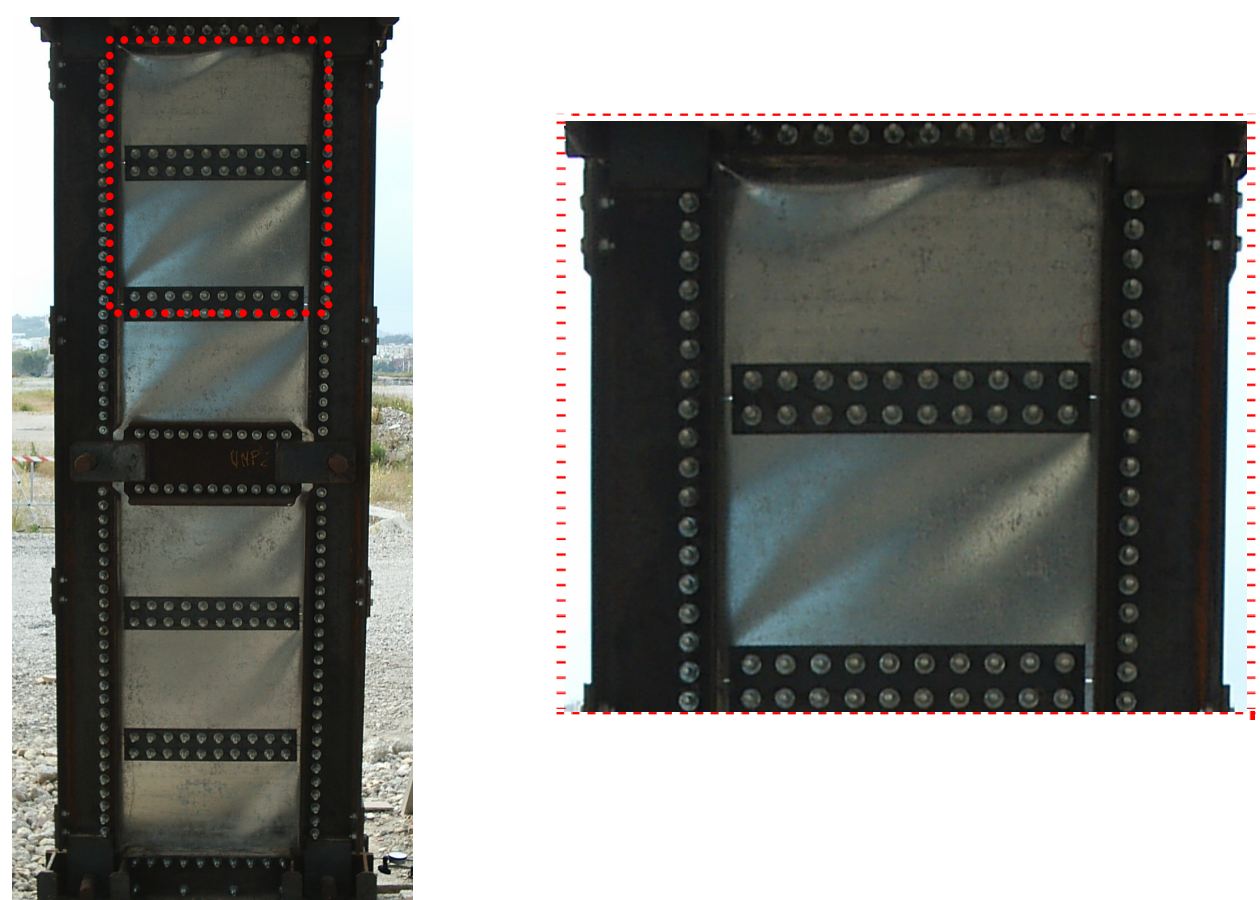

Figure 30. The Shear Panel Response during the Fifth Cycle of the Loading Test 

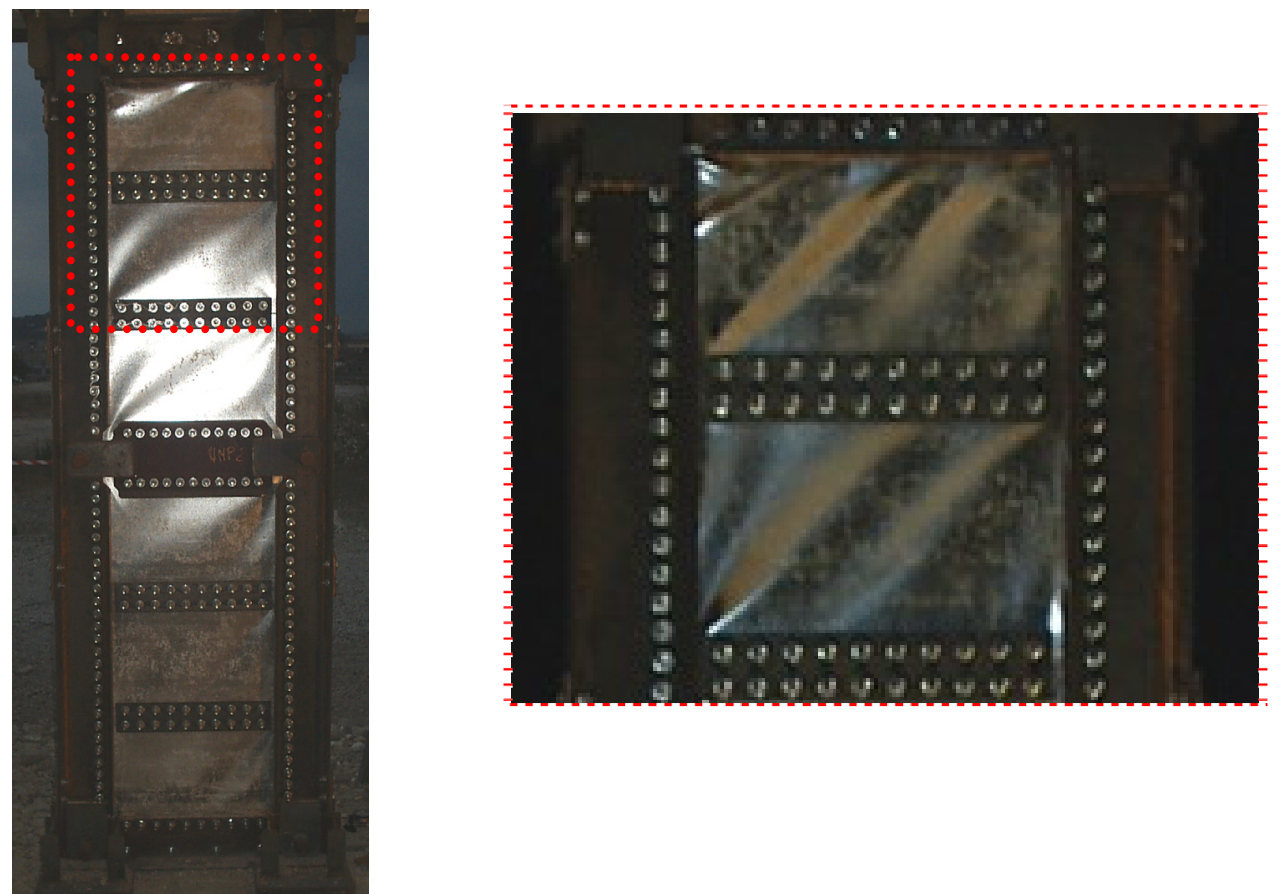

Figure 31. The Shear Panel Response during the Ninth Cycle of the Loading Test

In the twelfth cycle a partial plastic behaviour of the panel, with the significant development of permanent waves on each plate portion, appeared (Figure 32). In this phase, corresponding to an applied global load and displacement of $240 \mathrm{kN}$ and $42.80 \mathrm{~mm}$, respectively, the buckled shape occurred in the upper panel portion during the initial loading stage disappeared.
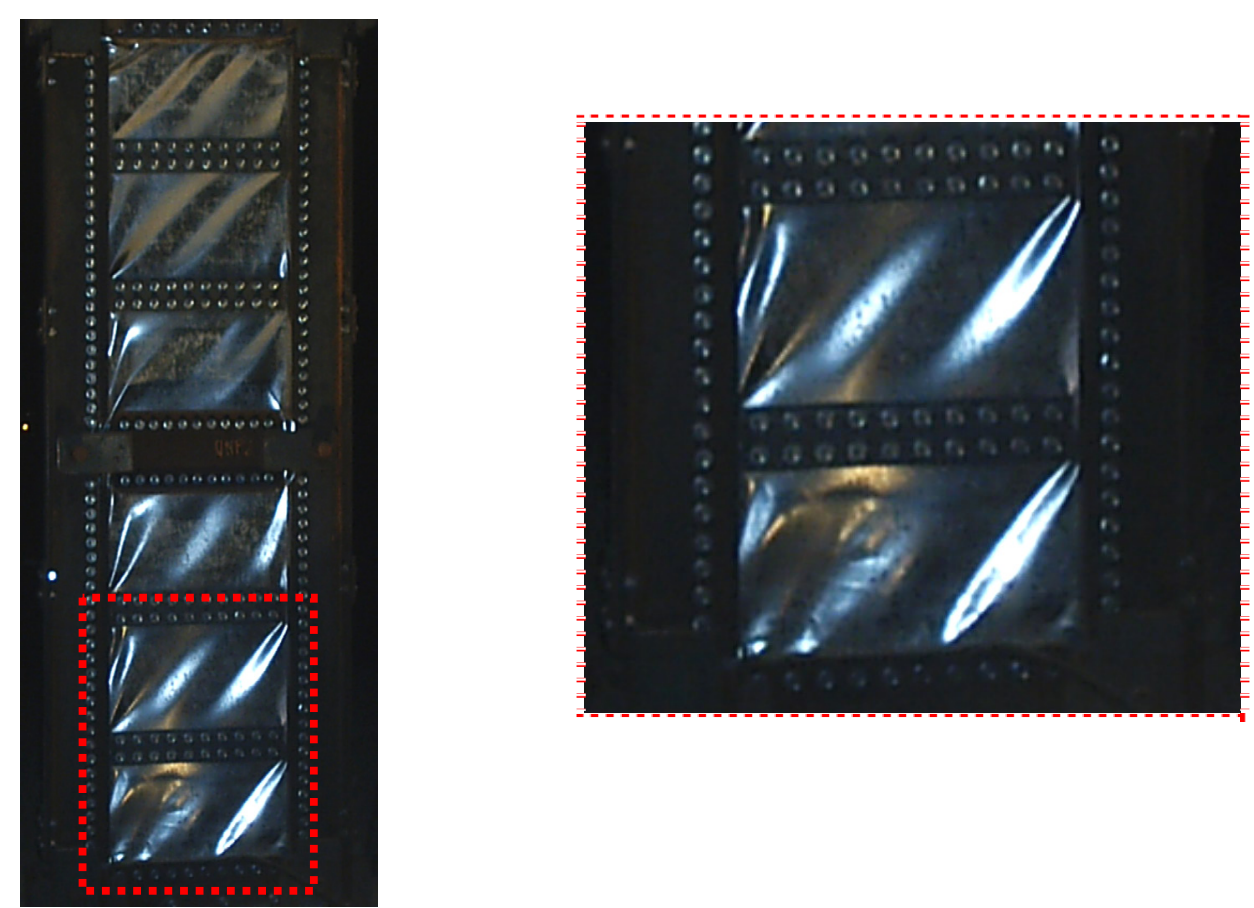

Figure 32. The Shear Panel Response during the Twelfth Cycle of the Loading Test

The final deformed shape of shear panels at the end of the test $\left(15^{\text {th }}\right.$ cycle), where a force of $300 \mathrm{kN}$ and a displacement of $87.55 \mathrm{~mm}$ were applied, is depicted in Figure 33, where it is apparent as the entire panel surface is strongly involved in plastic deformation. 
Finally, experimental results have confirmed the effectiveness of the proposed design procedure since the consequently implemented non linear finite element model of the steel shear panel exhibited a very good agreement in terms of deformed shape with the real final deformation of the used system, as shown in Figure 33. The same results have been also achieved by modeling the steel shear panel through equivalent truss elements, according to the strip model theory, as it is exhaustively reported in [15]
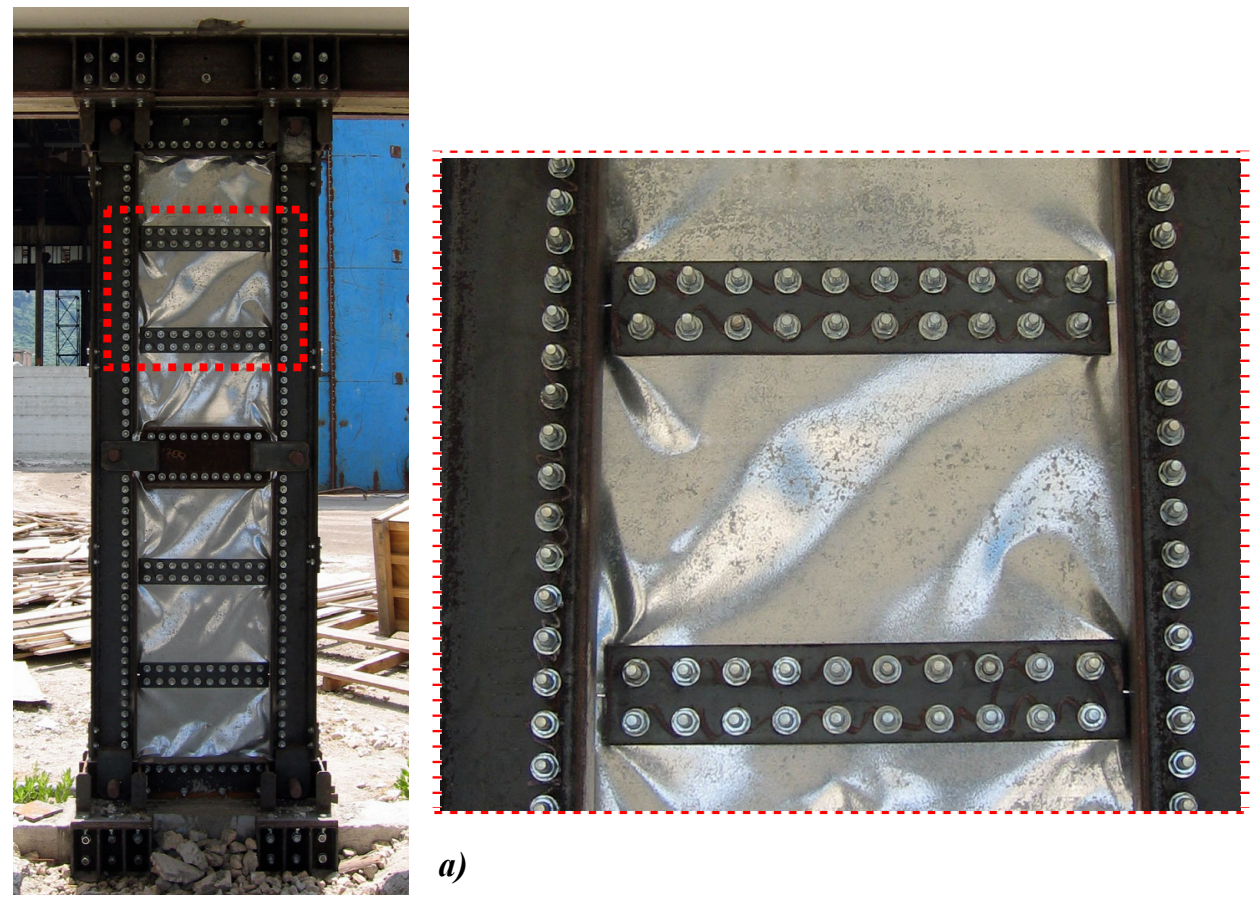

Figure 33. Final Experimental (a) and Numerical (b) Deformed Shape of the Tested Shear Panel

\section{CONCLUSIONS}

In the current paper the use of slender steel panels as seismic retrofitting systems of existing RC structure has been analysed. The retrofitting design, developed on the basis of a preliminary evaluation of the load-carrying capacity of the bare structure, has been set-up according to the performance based design methodology, allowing the definition of the testing panel geometry. On the basis of the panel structural configuration obtained from the design phase, an experimental test has been carried out on the compound RC frame - steel panel structure, showing as the proposed retrofitting system is able to increase both the strength and the stiffness of the original building up to 10 and 2 times, respectively.

Based on such results the proposed system appears to be suitably used for the seismic upgrading of existing reinforced concrete frame characterised by significant structural deficiencies.

\section{ACKNOWLEDGEMENTS}

This paper has been developed within both the European FP6 project "Earthquake Protection of Historical Buildings by Reversible Mixed Technologies" (PROHITECH) and the research theme n.5 "Development of innovative approaches for the design of steel and composite structures" of the Italian project RELUIS. 


\section{REFERENCES}

[1] Mazzolani, F.M., Dolce, M., Landolfo, R. and Nicoletti, M., "Seismic Upgrading of RC Buildings by Means of Innovative Techniques: The ILVA-IDEM Project", Proceedings of the $11^{\text {th }}$ National Congress "L'ingegneria Sismica in Italia", Genoa, 2004, CD-ROM.

[2] De Matteis, G., Landolfo, R. and Mazzolani, F.M., "Seismic Response of MR Steel Frames with Low-yield Steel Shear Panels", Journal of Structural Engineering 2003, Vol. 25, pp. 155-168.

[3] De Matteis, G., Mazzolani, F.M. and Panico, S., "Steel Bracings and Shear Panels as Hysteretic Dissipative Systems for Passive Control of MR Steel Frame", Costruzioni Metalliche, 2003, Vol. 6, pp. 41-53.

[4] De Matteis, G., Formisano, A., Mazzolani, F.M. and Panico, S., "Experimental Tests and Numerical Simulation on Stiffened Pure Aluminium Shear Panels", Proceedings of the $10^{\text {th }}$ International Conference on Civil, Structural and Environmental Engineering Computing, Rome, 2005, CD-ROM.

[5] Astaneh-Asl, A., "Seismic Behavior and Design of Steel Shear Walls", Steel TIPS Report, Structural Steel Educational Council, Moraga, CA, 2001.

[6] Mazzolani, F. M. (co-ordinator \& editor), "Seismic upgrading of RC buildings by advanced techniques - The ILVA-IDEM Research Project", Polimetrica International Scientific Publisher, Monza, 2006, ISBN 88-7699-038-0.

[7] ATC-40, "Seismic Evaluation and Retrofit of Concrete Buildings", Applied Technology Council, Report n. SSC 96-01, 1996.

[8] De Matteis, G. and Mistakidis, E.S., "Seismic retrofitting of moment resisting frames using low yield steel panels as shear walls", Proceedings of the $4^{\text {th }}$ International Conference STESSA 2003, "Behaviour of Steel Structures in Seismic Areas”, Naples, 2003, pp. 677-682.

[9] Mistakidis, E.S., De Matteis, G., Formisano, A., "LYM Shear Panels as an Alternative for the Seismic Upgrading of Concrete Structures", Advances in Engineering Software, Elsevier, Noor, A.K., Adey, R.A. and Topping, B.H.V. editors, ISSN 0965-9978, N. 38, 2007, pp. 626-636.

[10] Hibbitt, Karlsson, Sorensen, Inc., ABAQUS/Standard, v. 6.4, Patwtucket, USA, 2004.

[11] Formisano, A., De Matteis, G., Panico, S., Calderoni, B. and Mazzolani, F.M., "Full-scale Test on Existing RC Frame Reinforced with Slender Shear Steel Plates", Proceedings of the $5^{\text {th }}$ International Conference STESSA 2006 "Behaviour of Steel Structures in Seismic Areas", Yokohama, 2006, pp. 827-834.

[12] Sabouri-Ghomi, S., Ventura, C. and Kharrazi, M.H.K., "Shear Analysis and Design of Ductile Steel Plate Walls", Proceedings of the $4^{\text {th }}$ International Conference STESSA 2003, "Behaviour of Steel Structures in Seismic Areas", Naples, 2003, pp. 189-195.

[13] Canadian Standards Association (CSA), "Limit States Design of Steel Structures", CAN/CSA S16-01, Canadian Standards Association, Willowdale, Ont., Canada, 2001.

[14] Formisano, A., De Matteis, G., Mazzolani, F.M. and Panico, S., "Seismic Retrofitting of an Existing RC Structure by Means of Steel Shear Panels: the Proposed Design Solution”, Proceedings of the $20^{\text {th }}$ C.T.A. National Congress, Ischia, 2005, pp. 475-482.

[15] Formisano, A., De Matteis, G., Panico, S and Mazzolani, F.M., "Metal Shear Panels as Innovative System for Seismic Upgrading of Existing RC Buildings: from Numerical Analyses to Full-scale Experimental Tests", Proceedings of the 15th International Conference on the Computational Mechanics in the UK (ACME 2007), Glasgow, 2-3 April 2007. 